Please do not remove this page

RMIT

UNIVERSITY

\title{
Fixed-wing MAV attitude stability in atmospheric turbulence-Part 2: Investigating biologically-inspired sensors
}

Mohamed, Abdulghani; Watkins, Simon; Clothier, Reece; Abdulrahim, Mujahid; Massey, Kevin; Sabatini, Roberto

https://researchrepository.rmit.edu.au/esploro/outputs/9921859413201341/filesAndLinks?institution=61RMIT_INST\&index=null

Mohamed, A., Watkins, S., Clothier, R., Abdulrahim, M., Massey, K., \& Sabatini, R. (2014). Fixed-wing MAV attitude stability in atmospheric turbulence-Part 2: Investigating biologically-inspired sensors. Progress in Aerospace Sciences, 71, 1-13. https://doi.org/10.1016/j.paerosci.2014.06.002

Document Version: Accepted Manuscript

Published Version: https://doi.org/10.1016/j.paerosci.2014.06.002

Repository homepage: https://researchrepository.rmit.edu.au

(C) 2014 Elsevier Ltd

Downloaded On 2023/04/26 09:17:31 +1000

Please do not remove this page 
Thank you for downloading this document from the RMIT Research Repository.

The RMIT Research Repository is an open access database showcasing the research outputs of RMIT University researchers.

RMIT Research Repository: http://researchbank.rmit.edu.au/

\section{Citation:}

Mohamed, A, Watkins, S, Clothier, R, Abdulrahim, M, Massey, K and Sabatini, R 2014, 'Fixed-wing MAV attitude stability in atmospheric turbulence-part 2: Investigating

biologically-inspired sensors', Progress in Aerospace Sciences, vol. 71, pp. 1-13.

See this record in the RMIT Research Repository at:

https://researchbank.rmit.edu.au/view/rmit:28175

Version: Accepted Manuscript

Copyright Statement: (c) 2014 Elsevier Ltd

Link to Published Version:

http://dx.doi.org/10.1016/j.paerosci.2014.06.002 
Important Notice: This is the authors' pre-publication version. This paper does not include changes and revisions arising from the peer review and publishing processes. The final definitive copy, which should be used for all referencing, is published at:

http://www.sciencedirect.com/science/article/pii/S0376042114000621

DOI: $10.1016 /$ j.paerosci.2014.06.002 


\title{
Fixed-Wing MAV Attitude Stability in Atmospheric Turbulence PART 2: Investigating Biologically- Inspired Sensors
}

\author{
Mohamed, A. ${ }^{\text {a }}$ Watkins, S. ${ }^{\text {a }}$ Clothier, R. ${ }^{\text {a }, ~ A b d u l r a h i m, ~ M . ~}{ }^{\text {a }}$, \\ Massey, K. ${ }^{\mathrm{a}}$, and Sabatini R. ${ }^{\mathrm{a}}$ \\ ${ }^{\text {a} R M I T ~ U n i v e r s i t y, ~ M e l b o u r n e, ~ V i c t o r i a ~} 3001$
}

abdulghani.mohamed@ @mit.edu.au, simon.watkins@ rmit.edu.au, reece.clothier@ $\underline{\text { rmit.edu.au, }}$ mujahid.abdurahim@rmit.edu.au, kevin.massey@rmit.edu.au, roberto.sabatini@ rmit.edu.au

\begin{abstract}
Challenges associated with flight control of agile fixed-wing Micro Air Vehicles (MAVs) operating in complex environments is significantly different to any larger scale vehicle. The micro-scale of MAVs can make them particularly sensitive to atmospheric disturbances thus limiting their operation. As described in Part 1, current conventional reactive attitude sensing systems lack the necessary response times for attitude control in high turbulence environments. This paper reviews in greater detail novel and emerging biologically inspired sensors, which can sense the disturbances before a perturbation is induced. A number of biological mechanoreceptors used by flying animals are explored for their utility in MAVs. Man-made attempts of replicating mechanoreceptors have thus been reviewed. Bio-inspired flow and pressure-based sensors were found to be the most promising for complementing or replacing current inertial-based reactive attitude sensors. Achieving practical implementations that meet the size, weight and power constraints of MAVs remains a significant challenge. Biological systems were found to rely on multiple sensors, potentially implying a number of research opportunities in the exploration of heterogeneous bio-inspired sensing solutions.
\end{abstract}

Key words: Micro Air Vehicle (MAV), turbulence disturbance rejection, attitude control sensors, gust load alleviation, bio-inspired flow sensors, biological systems, mechanoreceptors

\section{Introduction}

The phenomenon of atmospheric turbulence and its impact on Micro Air Vehicle (MAVs) is discussed in Mohamed et al. (2014b). Attitude stability is becoming more of a concern with the introduction of increasingly smaller Unmanned Aerial Vehicles (UAVs) and is considered critical for MAVs, which face greater stability issues due to their miniature size. Low-level flight in the Atmospheric Boundary Layer (ABL) without sufficient gust mitigation is hazardous. Turbulence intensity rapidly increases as height above ground approaches zero (Walshe, 1972). The presence of high turbulence intensities can significantly deteriorate the attitude stability of MAVs (McCarley and Wickens, 2004, Orr et al., 2005, Galinski, 2006, Galiński and Żbikowski, 2007, Lissaman, 2009, Shyy et al., 2010) and is a major constraint 
on MAV operations. Current MAVs face operational constraints due to severe turbulence at low altitudes, which is optimum for sensor resolution in Intelligence, Surveillance, and Reconnaissance (ISR) missions. Hence, increasing the operational spectrum of MAVs in turbulent conditions is essential to allow MAVs to reach their full operational potential. Increased attitude stability and reduced control response time is crucial to attitude control, or disturbance rejection systems.

A review of conventional sensors has been presented in the first part of this paper (Mohamed et al., 2014a). Conventional inertial-based sensors can lack the required response-time since they measure the response of the vehicle rather than the disturbance itself. Sensing disturbances and reacting to them as early as possible will suppress perturbations significantly, and consequently increasing the operational days per year. Other nonbiologically inspired sensors that can sense flow disturbances include Light Detection and Ranging (LiDAR) and radar. These sensors may be unsuitable for MAV adaption in their current form but are mentioned for completion. Size Weight and Power (SWaP) constraints currently limit the applicability of these technologies to MAV. This paper focuses on emerging sensing approaches inspired by nature.

Nature's fliers have evolved to fly successfully close to the ground in turbulent conditions thus it is sensible to turn to nature for design cues. Biologically inspired MAVs are not new (Shang et al., 2009, Nakata et al., 2011, O'Hara and Palazotto, 2012, Croon et al., 2012). This paper explores novel and emerging sensors, many of which are inspired by biological systems observed in nature. In this paper we explore how nature can inspire novel sensory systems that have the potential to enhance attitude control performance of MAVs. Section 3 of this paper reviews the relevant biological systems used by flying birds and insects to sense and react to turbulence. These biological systems are the inspiration for many novel and emerging sensors relevant to MAVs. Man-made attempts to replicate the functioning of these biological systems are presented in Section 4.

\section{The Gust Perturbation Process}

There are a number of unique constraints imposed on MAVs as a consequence of their micro scale and operational requirements. Mohamed et al. (2014b) provide a detailed review of these constraints and their contribution to attitude instability. Attitude control of MAVs is a demanding task in terms of the control input required for straight and level flight in turbulent flow. MAVs are required to safely manoeuvre and maintain the intended flight path in obstacle-rich environments. The presence of winds in such environments can prevent an MAV from reaching its pre-programmed waypoints (Orr et al., 2005). This degradation in performance puts the aircraft at risk and often leaves the MAV unable to complete its mission (White et al., 2012). Flight in such turbulent conditions is hazardous and there can be instances where the MAV is overwhelmed by the atmospheric turbulence and the induced local wake of the surrounding obstacles leading to aircraft loss.

MAVs predominantly employ Micro-electro-mechanical Systems (MEMS) inertial-based sensors for attitude sensing and navigation (Mohamed et al., 2014b, Mohamed et al., 2014a). 
These comprise of MEMS gyroscopes and accelerometers. Such sensors measure the inertial response of the MAV to an input disturbance. The reactive nature of these sensors limits the time-response of any attempt to mitigate the effect of the disturbance. More effective attitude control systems will need to employ sensors that can sense the disturbing phenomena rather than the vehicle's response to a disturbance. These sensors are referred to herein as phaseadvanced sensors. The gust perturbation process adapted from (Mohamed et al., 2014b) can aid the exploration of different sensing approaches to potentially measure the preceding physical phenomena of the cause of motion perturbation (see Figure 1). When an oncoming gust is encountered by a MAV's wing, the oncoming velocity vector is perturbed resulting in an Angle of Attack (AoA) variation in magnitude accompanied by a change in yaw and pitch angles. Of these three aspects of the perturbation, the pitch angle variation was identified as the most significant for MAV's attitude stability (Thompson et al., 2011).

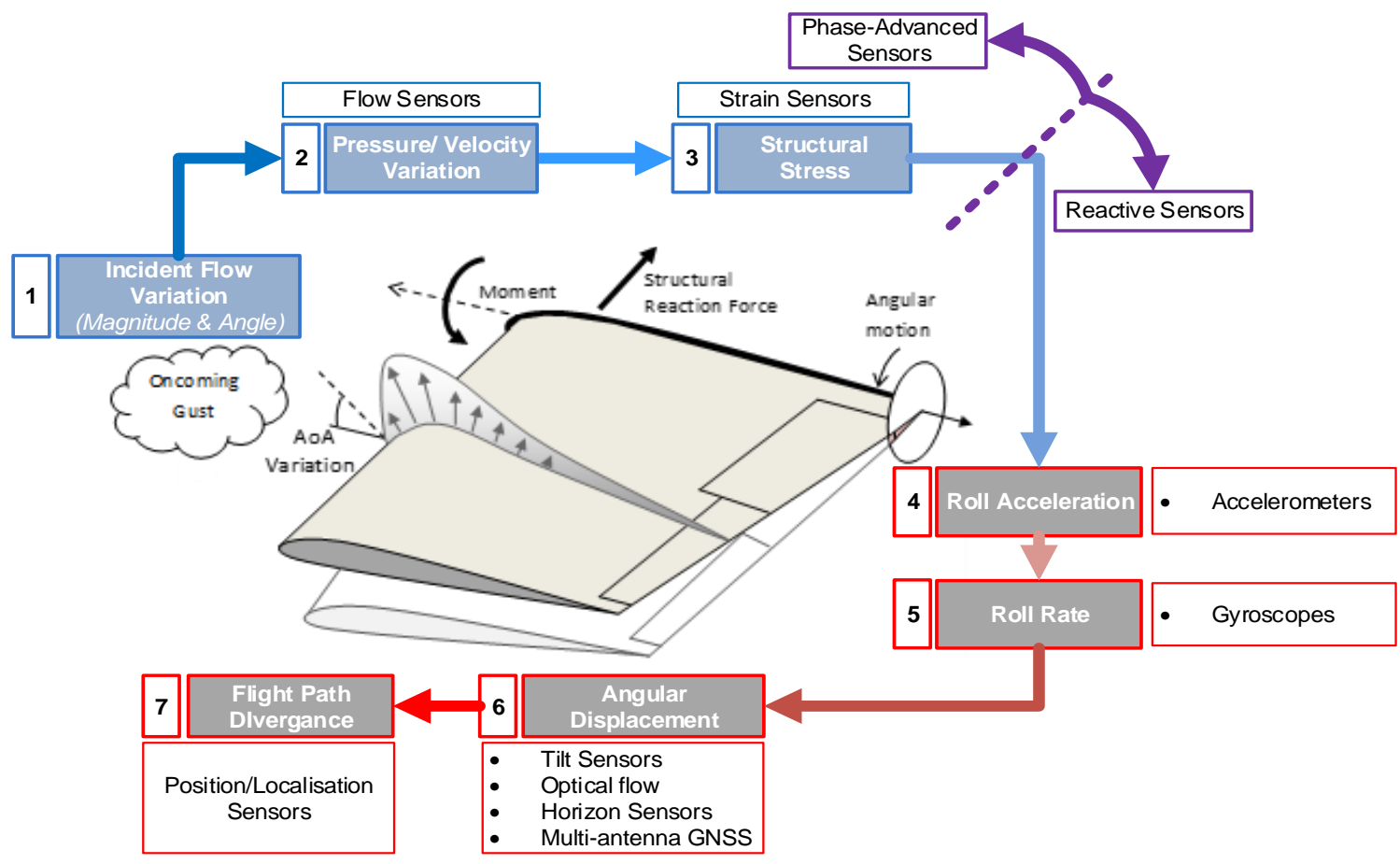

FIGURE 1: THE MEASURABLE SEQUENCE OF EVENTS CAUSED BY ADVECTION OF TURBULENT PROPERTIES OVER A WING AND THEIR ATTRIBUTED SENSORS ADAPTED FROM (MOHAMED ET AL., 2014B)

Sensors that can detect the disturbing phenomena (or their effect) as early as possible have the potential to reduce the response-lag of attitude control systems. Reducing lag can lead to improved MAV control in turbulence. The following section explores biological systems that can detect the gust-induced events in the early stages of the gust perturbation process (Figure 1). Detecting these events is potentially advantageous in that it provides phase-advanced information to the control system for improved attitude control. 


\section{Biological Sensory Systems}

Animal flight in turbulence has been studied since the 1900's (Hankin, 1913). Animals employ a combination of integrated sensory systems linked directly to their central nervous system. It is therefore useful to know whether artificial replication of such systems can aid attitude control. Although challenging for man-made aerial robotics, birds and insects seem to hold relatively straight and level flight even under high turbulence conditions. Different animals and aircraft are grounded by varying wind speeds (Table 1) and high turbulence intensities (Watkins et al., 2006). Intuitively, the primary factors determining an animal's grounding wind-speeds (i.e. maximum endured wind-speed) are the sophistication and complexity of their control and sensory systems, and their physical size. Birds such as Kestrels can withstand elevated levels of turbulence while hovering and maintaining a spatial "head-lock" with a high degree of accuracy for spotting moving prey below. These birds provide an inspiration and benchmark for man-made vehicles of similar size. It is thus wise to consult nature's flyers for technological cues, to enhance attitude control of MAVs and explore their biological sensors for inspiration, which has optimally evolved to sense flightrelated parameters.

TABLE 1: FLYING SPEEDS OF ANIMALS AND AIRCRAFT, REPRODUCED FROM (TENNEKES, 2009)

\begin{tabular}{llll}
\hline Beafort no. & Airspeed & Windspeed $(\mathbf{m} / \mathbf{s})$ & Cruising speed of \\
\hline $\mathbf{1}$ & Light air & $0.5-1$ & Butterflies, damselflies \\
$\mathbf{2}$ & Light breeze & $2-3$ & Gnats, flies, dragonflies \\
$\mathbf{3}$ & Gentle breeze & $4-5$ & Human-powered airplanes \\
$\mathbf{4}$ & Moderate breeze & $6-8$ & Bees, wasps, beetles \\
$\mathbf{5}$ & Fresh breeze & $9-11$ & Sparrows, starlings, swallows \\
$\mathbf{6}$ & Strong breeze & $11-13$ & Crows, gulls, falcons \\
$\mathbf{7}$ & Near gale & $14-17$ & Plovers, knots, godwits \\
$\mathbf{8}$ & Gale & $18-21$ & Swans, ducks, geese \\
$\mathbf{9}$ & Strong gale & $21-24$ & Sailplanes \\
$\mathbf{1 0}$ & Storm & $25-28$ & Home-built aircraft \\
$\mathbf{1 1}$ & Violent storm & $29-32$ & Diving hawks \\
$\mathbf{1 2}$ & Hurricane & $>32$ & Diving falcons \\
\hline
\end{tabular}

However, there are a number of unexplored sensory receptors used by flying animals that could be replicated and adapted to aerial robotics. These biological receptors sense different parameters such as scent, flexure, or light. Inputs from these receptors are often combined and fed through nerves to the brain. Receptors relevant to attitude control include photoreceptors and mechanoreceptors. Photoreceptors have been extensively studied in the context of flight control (Srinivasan et al., 1999, Chahl et al., 2011), however exploitation of mechanoreceptors for flight control is not well established. The following subsections aim to provide insight into insect and avian mechanoreceptors before exploring possible man-made replicas.

\subsection{Insect Mechanoreceptors}

Flying insects are 'sensor-rich' in contrast to aircraft (Zbikowski, 2004). Insect sensory systems contain multiple transducers (Taylor and Krapp, 2007), with outputs from which are fused and input to the control system. In their detailed study, Taylor and Krapp (2007) 
identified flying insects' sensory systems, which comprise of; visual, airflow, inertial, and wing load sensing.

Mechanoreceptors are found almost entirely over an insect's body. These sensory receptors respond to mechanical changes that are then signalled to the brain through nerves for processing. There are many types of mechanoreceptors associated with sensing various mechanical changes such as bending, stretching, vibration or other mechanical disturbances. Apart from allowing the insect to detect movement in its environment, they provide the insect with information regarding its body position and orientation, which is known as proprioception. These receptors generate feedback responses that allow the insect to adapt to the corresponding condition. There can also be mechanoreceptors embedded in the wing, which contribute to flight control (Taylor and Krapp, 2007). Relevant wing mechanoreceptors and their sensing mechanism are explored below.

\subsubsection{Wind-Sensitive Hairs}

Insects are covered in trichoid sensilla ${ }^{1}$, found near the base of hairs, which can detect airflow levels only evident acoustically (Levin and Miller, 1996). These receptors generate a nerve signal proportional to the magnitude of the movement of the hair. The nerve signal response rate of trichoid sensilla is a function of wind speed, and direction (Camhi, 1969) in addition to temperature (Smola, 1970). Taylor and Krapp (2007) state that wind-sensitive hairs associated with flight control are located on the head capsule and the compound eyes of some insect species. Their location on the head is practical, since the Signal-to-Noise Ratio (SNR) would be highest in that region due to the laminar flow existing here. It is therefore believed that these hairs are used to determine the air velocity vector. The study also speculates that trichoid sensilla found on the wings could be used for flight control although there is no evidence yet to support this proposition. A later study by Ai et al. (2010), identified a number of bristles along the wing margins of the silkworm moth, where it was shown that these vibration receptive sensilla inform the control system about the wing beat frequency (see Figure 2). Finally Taylor and Krapp (2007) explain that it is an over simplification to consider wind-sensitive hairs as purely measuring aerodynamic states such as angle of attack, sideslip or velocity magnitude, since their inputs are integrated within the insects visual system to output multi-modal responses.

\footnotetext{
${ }^{1}$ A type of mechanoreceptor which can detect vibrations
} 

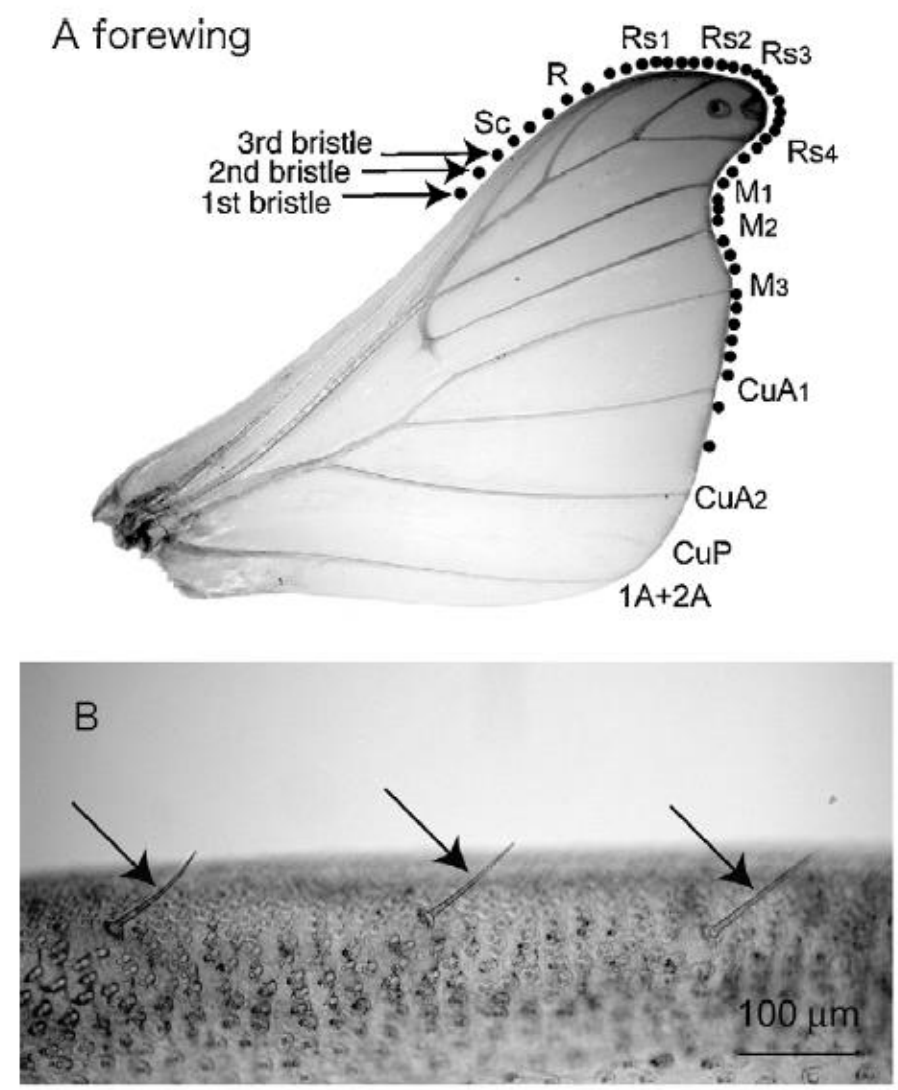

FIGURE 2: VIBRATION SENSITIVE BRISTLES ON THE FOREWING OF THE SILKWORM MOTH (A) DISTRIBUTION OF THE BRISTLES (B) BRISTLES ALIGNED ALONG THE ANTERIOR MARGIN OF THE WING. (AI ET AL., 2010)

\subsubsection{Wing Load Sensing}

Campaniform sensilla ${ }^{2}$ are another kind of mechanoreceptor found throughout the insect's body, but more relevantly in the wing. Although the location of campaniform sensilla on insect wings is highly stereotyped within a species (Taylor and Krapp (2007), they are mostly clustered near the wing base. Ando et al. (2011), studied the campaniform sensilla of the hawkmoth, Agrius convolvuli, and its contribution to flight control. They found evidence suggesting that the hawkmoth uses these receptors to determine its wing loading during flight. Taylor and Krapp (2007) confirmed the latter by explaining that the campaniform sensilla mostly operate as load sensors or proprioceptors, allowing regulation of the wing's kinematics in some species. Further research showed that the campaniform sensilla are coupled with the ocelli $^{3}$, thus further complicating its operation (Elson, 1987). According to Taylor and Krapp (2007), this coupling combines state feedback and force feedback into a single signal, which is used by the insect's control system to encode wing deformations associated with motion patterns.

\footnotetext{
${ }^{2}$ A type of mechanoreceptor found in insects which responds to flexure inducing mechanical stress

${ }^{3}$ An arrangement of "simple eyes" used by insects to detect the orientation
} 


\subsection{Bird Mechanoreceptors}

Avian wings are rich with various mechanoreceptors, which influence flight control. They are located near the follicles of feathers allowing a bird to know its airspeed, detect a stall and turbulence (Hörster, 1990a, Hörster, 1990b, Necker, 1985a, Necker, 1985b, Brown and Fedde, 1993). Each mechanoreceptor type has a unique response characteristic optimised for a specific task. This varies from a slowly adapting mechanoreceptor to a rapidly adapting one (Iggo and Gottschaldt, 1974). A bird gathers flow information through its wing sensors to respond to turbulence by changing its heartbeat frequency, wing pitch angle and extension of primary feathers, or the alula to counteract the aerodynamic changes (Nachtigall and Kempf, 1971). Avian cutaneous wing receptors are categorised as free-nerve endings and encapsulated endings. Free-nerve endings are used for temperature and pain sensing, while encapsulated endings are mechanoreceptors, also known as sensory corpuscles (Gottschaldt, 1985, Sturkie and Whittow, 2000). There are various corpuscles distinguishable in birds (Figure 3), however, only Herbst corpuscles ${ }^{4}$ are considered in this paper for their known contribution to flight control in birds as flow and pressure sensors (\$3.2.1). Additionally, stretch receptors embedded in limb muscles are discussed for their hypothesised use as load sensors $(\$ 3.2 .2)$.
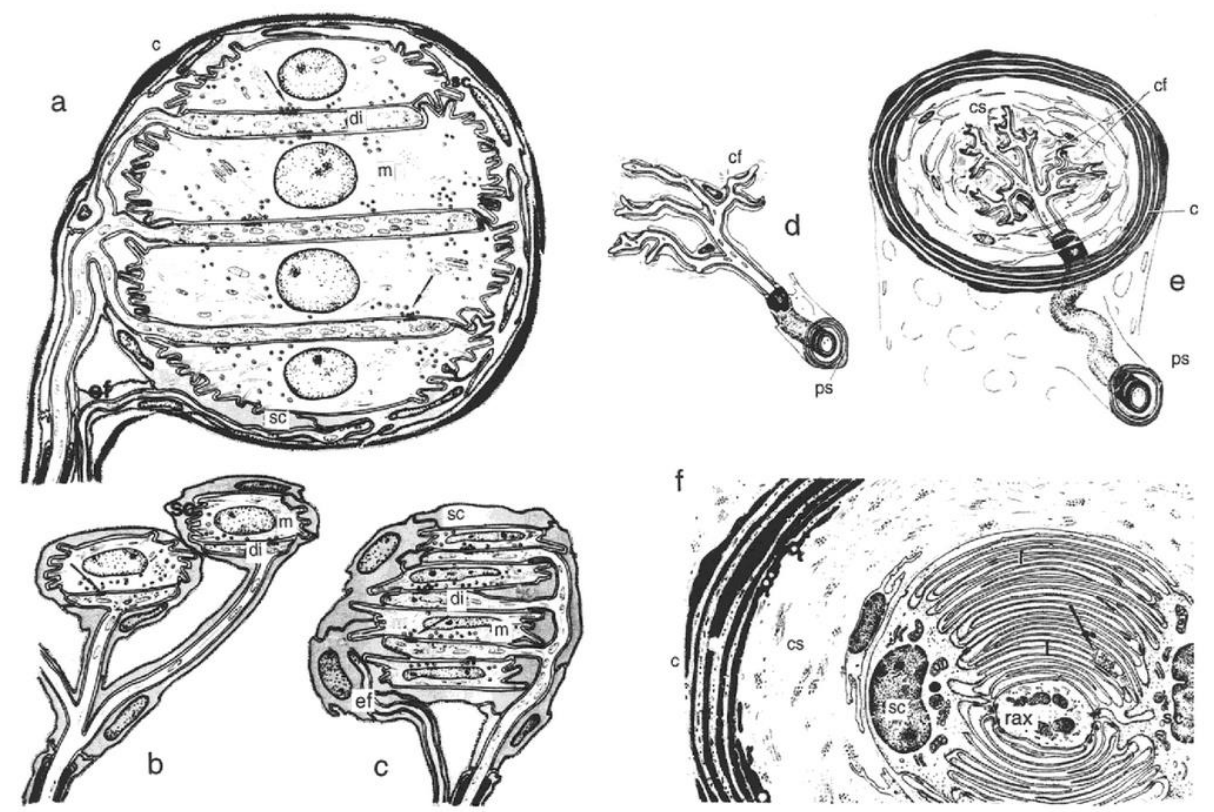

FIGURE 3: AVIAN SKIN MECHANORECEPTOR TYPES: (A) GRANDRY CORPUSCLES (B) MERKEL CELL RECEPTORS (C) MERKEL CELL CORPUSCLE (D) FREE STRETCH RECEPTOR ENDING (E) RUFFINI CORPUSCLE (F) HERBST CORPUSCLE (STURKIE AND WHITTOW, 2000)

\subsubsection{Flow and Pressure Sensing}

Herbst corpuscles are another common avian receptor, found in decreasing order in the head, tail, neck, wing, back, and abdomen (Stammer, 1961). These receptors are commonly distributed in feathered skin and are associated with feather follicles and feather muscles (Stammer, 1961, Winkelmann and Myers III, 1961, Ostmann et al., 1963, Andres and von

\footnotetext{
${ }^{4}$ Nerve endings found in feather follicles which sense vibration
} 
During, 1990). Herbst corpuscles are vibration receptors that are tuned to a specific frequency range and displacement amplitude depending on their location. It is also evident that flying birds are granted with larger quantities of Herbst corpuscles, than their non-flying counterparts (Sturkie and Whittow, 2000). Their location is also unique within a species, where Brown and Fedde (1993) reported that primary feathers of chicken, Gallus domesticus, do not respond to vibrations, while Hörster (1990b) reported that primary feathers of pigeons are highly sensitive to vibrations. The latter thus illustrates that vibration receptors exist at primary feather follicles of pigeons in contrast to chickens, which have vibration receptors only in secondary feathers. Herbst corpuscles are also known to be directionally sensitive, where a preferential orientation to the feather follicles is evident for optimising the transmission of vibrations to the receptors (Hörster, 1990a). They are also densely clustered in certain areas such as the leading edge of the wing and the alula (Hörster, 1990a). These locations are critical for enhanced aerodynamic detection, providing the brain with phaseadvanced flow information. These receptors are primarily used for flight control, where they measure flow related parameters.

Avian biologists devised methods to locate wing receptors and determine their neural discharge response for various stimulations (Hörster, 1990a, Hörster, 1990b, Necker, 1985a, Necker, 1985b, Brown and Fedde, 1993, Sturkie and Whittow, 2000). Amplitude, frequency, and duration represented the stimulus testing parameters in these studies. Different areas were shown to react differently to various stimuli and at varied rates. Hörster (1990b) discovered that vibration receptors had varied vibrational response thresholds, which started firing after a certain frequency and amplitude were attained. These receptors where shown to be sharply tuned to a specific frequency range. The narrow frequency response of Herbst corpuscles represents high sensitivity for detecting specific airflow disturbances. It was reported that from the tested frequency range of $50-2000 \mathrm{~Hz}$, the narrow band of $800 / 900 \mathrm{~Hz}$ gave the highest sensitivity. The deflection amplitude at the best frequency response was $0.5-0.09 \mu \mathrm{m}$. In another study (Hörster, 1990a), a selection of receptors associated with a range of feathers in pigeon wings where mapped. Hörster (1990b) explains that the high firing rate induced at certain frequencies could represent a warning signal whenever these frequencies are attained. It is speculated that this warning could reflect dangerous flight behaviour such as an overspeed or simply high turbulence levels, thus grounding the animal. Another speculated function of the vibration receptors is for optimal adjustment of the wing's angle of attack for efficient flight.

Herbst corpuscles can detect variation of amplitude of the same frequency. Hörster (1990a) tested the discharge of a single Herbst corpuscle, where the frequency was fixed while varying its amplitude. Receptors' firing rate was found to be proportional to frequency amplitude, with a minimum response threshold. Avian wings also contain additional receptors that detect manual mechanical displacements of flight feathers. Brown and Fedde (1993) discovered slowly adapting receptors near flight feather follicles, which did not respond to the artificial airflow induced vibrations, but rather to the displacement of the feathers in any direction. Similar receptors were also found around the primary and covert follicles, and responded only to firm pressure. 
Vibrations are induced by the developing boundary layer along a wing. As the pressure distribution over the avian wing varies rapidly due to shear layer instabilities, the covert feathers over the wing vibrate correspondingly. The vibration frequency is proportional to the airflow velocity. Strong evidence suggests that birds use Herbst corpuscles to measure airspeed based on the feather-transmitted vibrational frequency and displacement amplitude. Brown and Fedde (1993) found a direct correlation between the neural discharge rate and the velocity of artificially induced stream of airflow blown over a selected feather. Through highspeed cinematography and photography of free-flying birds, rapid vibrations of distal ends of primary and secondary feathers are evident. Additionally, covert feathers were also observed to vibrate more violently during high pitch-angle manoeuvres, where they lift up chaotically while separation progresses towards the leading edge, see Figure 4. Certain covert feathers are also responsible for involuntary extension of the alula at high angles of attack.

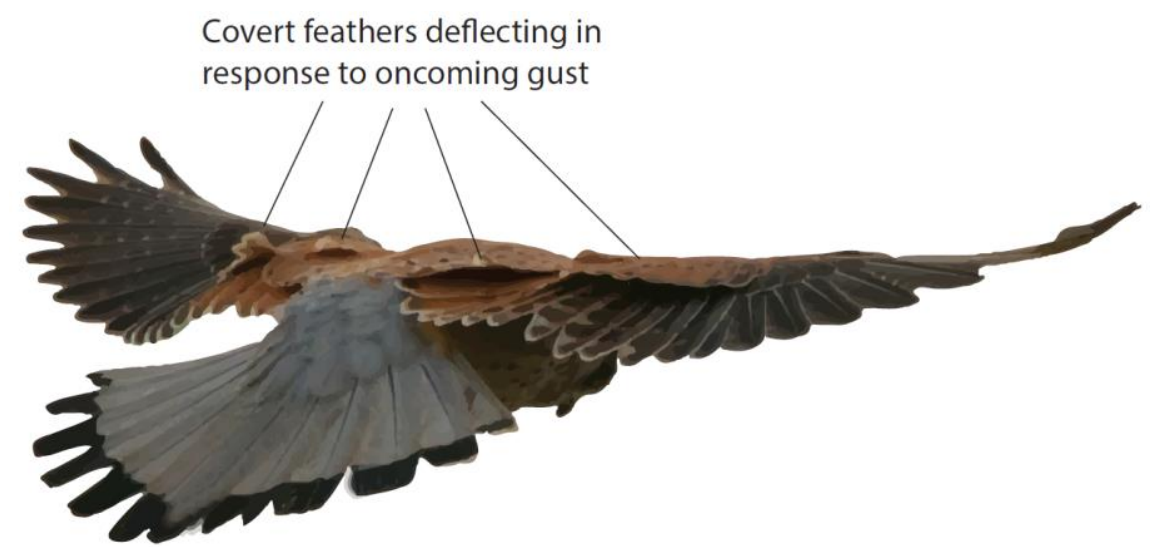

FIGURE 4: KESTREL'S COVERT FEATHERS DEFLECT IN RESPONSE TO DISTURBANCES MECHANORECEPTOR REPLICATION

\subsubsection{Load Sensing}

Vertebrates have stretch receptors embedded in their muscles that detect the amount and rate of change in muscle length. These receptors are known as muscle spindles and act as proprioceptors conveying spatial information of limbs to the brain. Although little information is available on the innervations of bird muscle spindles, they exist in limb muscles (Maier et al., 1971, Maier, 1992). It is therefore speculated that these stretch receptors are auxiliary to the cutaneous receptors allowing birds to determine gust-induced displacements of the entire wing structure relative to its centre of gravity. A simplifying analogy to the latter is when one extends a hand outside a window of a car travelling at a certain speed. The hairs of the forearm (cutaneous corpuscles) will sense the airflow over the skin surface, but as the hand is waved by varying its pitch angle, the shoulder and chest muscles (i.e. stretch receptors) will sense the displacement of the entire limb as its lift and drag forces are varied. In birds, both receptors complement each other, thus allowing birds to navigate through gusts gracefully.

\subsubsection{Summary of Biological Sensors}

From the previous discussion, it is evident that bird and insect receptors follow similar trends, where both sense wing loading at wing base, in addition to feathers and hairs which sense various flow qualities, as summarised in Figure 5. Load sensing is important for detecting 
overall pressure variation around a wing, while feathers and hairs are localised sensors optimized for detecting certain flow behaviours, such as separation, turbulence or an overspeed.

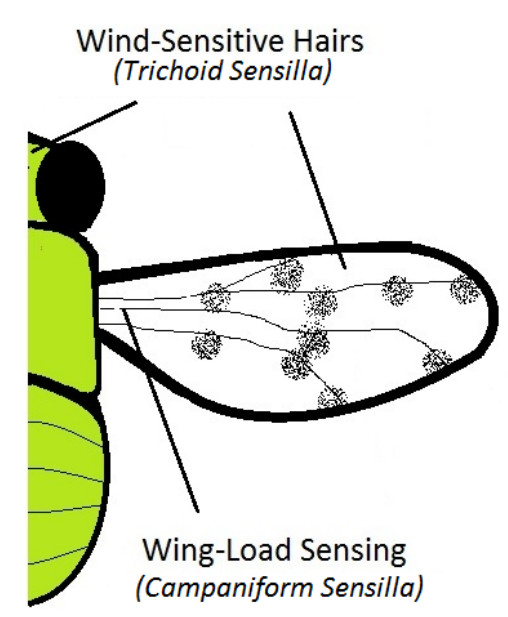

(a)

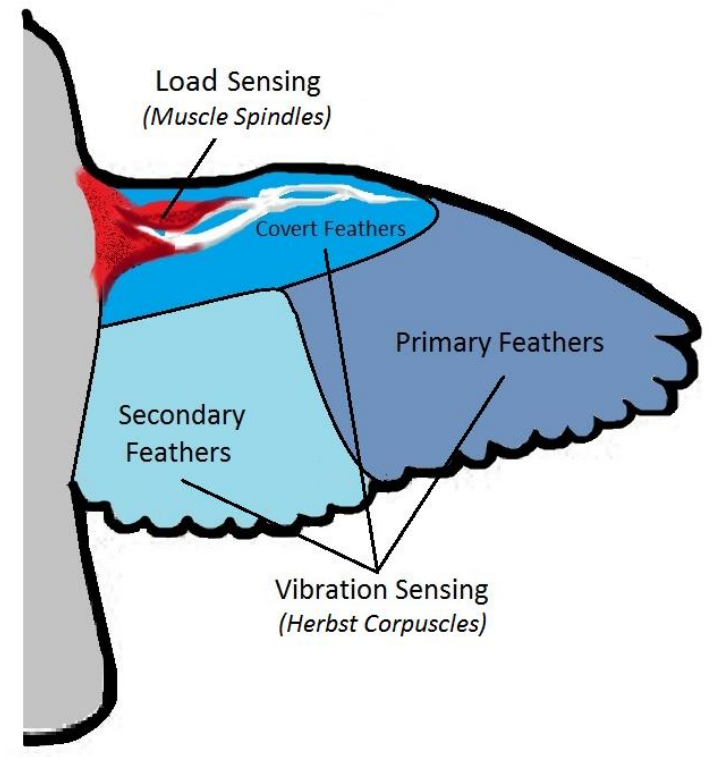

(b)

\section{FIGURE 5: MECHANORECEPTORS RELEVANT TO MAV ADAPTION (A) INSECT (B) BIRDS}

Both birds and insects are equipped with sensors that suit their physical, anatomical, and physiological properties, in addition to their operating environment. Size and flight regime play a major role in the variation of flight sensors where insects require higher frequency response and sensitivity to sense parameters of their nano-scale flight regime, in contrast to birds that use sensors tuned to a different flight regime. This can be explained by looking at individual sensory systems such as flow sensing. Birds use mechanoreceptors at the follicles of feathers to sense flow perturbations while insects use hairs, which are more sensitive to suit their miniature size, higher flapping rates and their operating Reynolds number. Another contributing factor to the differences in transducers is the varying complexity of their brains where birds can process complex information eliminating the need for having ocelli eyes for example, which is found in flying insects for quick detection of the horizon (Taylor and Krapp, 2007, Chahl et al., 2011).

From an adaption standpoint it is reasonable to explore those animals that have a similar operating regime and size to that of MAVs.For example, soaring birds are equivalent in size, speed and flight domain to that of many fixed-wing MAVs. Given the current technological level and bounding specifications of an MAV, birds seem to provide a better sensory solution, where they are a better representation of an MAV in terms of wingspan, mass and Reynold's number. The same argument could be applied to Nano Aerial Vehicles (NAVs), which could draw inspiration from the sensing solutions existent in the insect world. However, control systems for MAVs might benefit more from being simplified for reduced latencies associated 
with various technological limitations, making insect sensors more practical. Thus MAV sensors can take inspiration from both insects and birds.

\section{Biologically-Inspired Phase-Advanced Sensors}

The function of mechanoreceptors in detecting flow qualities can be replicated in a variety of ways. The follicles of hairs and feathers for instance involve different receptors, which can be particularly difficult to mimic since a single hair or feather can sense multiple parameters. Bio-mimicry (i.e. exact copy) is usually ineffective where biological structures often serve multiple purposes (Michelson, 2010). In contrast, bio-inspiration presents a practical approach whereby only the fundamentals are exploited for an implementation that suits the application. In-terms of mechanoreceptor replication this means that sensing flow parameters should be done through individual specialised sensors. For example, feathers can mechanically respond to a number of factors depending on their position and condition, such as variations in pressure, velocity, or angle of attack. Such parameters can be sensed individually through currently available sensors such as: thermal, strain or capacitance-based flow sensors. Their use in phase-advanced sensing is discussed later. There are many types of flow sensors. Flow sensors can be laboratory-based such as: Particle Image Velocimetry (PIV), Laser Doppler Anemometry (LDA), Light Detection and Ranging (LiDAR) and Radio Detection and Ranging (RADAR). However such sensors are generally too large to be incorporated into MAVs. The following subsections only explore bio-inspired sensors where it would be feasible to incorporate onboard a MAV.. Published attempts of using such sensors for attitude control are reviewed.

\subsection{MEMS Flow Sensors}

In birds, feathers act as deformable membranes, which detect flow variations while insects use hairs to perform the same function. Hence, strain-based flow sensors could be considered analogous to a feather and its receptor. The sensing element of such sensors, is fundamentally similar to the feather which deforms with changes in incident flow. The sensing element's vibration and/or deflection is typically measured with a physical mechanism such as electric resistance or capacitance which is conceptually similar in function to the Herbst corpuscles.

MEMS flow sensors are ideal for MAV employment due to their miniature size. They also have the benefits of low power dissipation and fast response time, which is essential for measuring turbulent flow (McNamara and Gianchandani, 2011). The miniature size of some of these sensors allows for their utilisation in small spaces without significantly interfering with the flow and consequently altering its behaviour. Miniature flow sensors are widely used for fluid measurements in various disciplines. The two most common flow sensing mechanisms, thermal and mechanical, are described in Table 2.

Basic implementations of miniature flow sensors measure localised flow velocity, while more complicated implementations can output a magnitude and direction of velocity (Figure 6). Often an array of sensors is used, similar to the multitude of sensors used by insects and birds, to overcome the limited information available from a single velocity vector. However, multi 
sensor implementations require a study into the optimum sensor placement and their corresponding density in a given area. This can be challenging in MAVs because of the SWaP constraints.

Flow sensors can be used for detecting the surface velocity distribution over critical locations of the wing area, such as the points of flow transition, reversal, or separation. Locating sensors thus requires a comprehensive understanding of the aerodynamics of the airfoil. Outof-plane mechanical flow sensing is another approach that can provide utility in measuring the fluctuations in the lift force over the wing (Figure 7 and Figure 8). Other unexplored implementations of mechanical flow sensors can possibly allow detection of Angle-of-Attack (AoA) variation, where a high density array can be embedded in the leading edge of the wings to detect the incoming flow's pitch angle.

TABLE 2: FLOW SENSOR TYPES

$\begin{array}{ll}\text { Sensor } & \text { Description } \\ \text { Type } & \text { Uses various techniques in the implementation of the sensing elements to measure airflow through } \\ \text { Mechanical } & \begin{array}{l}\text { deformation induced strain variation. Drag sensors have been developed which employ a cantilevered } \\ \text { structure that deforms due to viscous drag as shown in Figure } 7 \text { (Gass et al., 1993, Radhakrishnan and Lal, } \\ \text { 2003, 2005). Another interesting approach is the lift force sensor which employs a miniature flat plate } \\ \text { airfoil that deflects due to fluid flow as shown in Figure } 8 \text { (Svedin et al., 1998a, 1998b, 2003a, 2003b). } \\ \text { The deflection or pitch is strain measured and is consequently correlated with a lifting force. }\end{array} \\ & \begin{array}{l}\text { Based on the transport of heat into the moving fluid (Buder et al., 2005, Buder et al., 2007), there are } \\ \text { various implementations to measure the flow rate. Examples include measuring resistance of a heating } \\ \text { element, or the current required to maintain element temperature. There has also been early attempts at } \\ \text { integrating separate heating and temperature sensing as shown in Figure 9 (Stemme, 1986, Lofdahl et al., } \\ \text { 1989). Another form of this approach uses multiple temperature sensors arranged symmetrically around } \\ \text { the heating element which provides additional directional information (Kim et al., 2003, Kim et al., 2004, } \\ \text { Ohnstein et al., 1990, Park et al., 2003, Tan et al., 2007). This approach can be used for two-dimensional } \\ \text { in-plane measurement of flow. Out-of-plane sensing has also been studied which offers improved response } \\ \text { times, lower power requirements, and improved flow coupling (Ebefors et al., 1998, Chen et al., 2002). }\end{array} \\ & \begin{array}{l}\text { However, thermal based flow sensors can be sensitive to the operational environment impacting } \\ \text { performance. }\end{array}\end{array}$

\subsubsection{Application to MAVs}

Harsh environments, which are typical of some MAV missions, can have detrimental effects on the performance of flow sensors. A practical implementation must address several design considerations. For example, operating in high temperatures can "introduce error" degrading performance of thermal-based flow sensors. Mechanical flow sensors may also be challenged by rain, elevated humidity or fine airborne particles, which can all cause stiction of a cantilevered sensing element. High impact forces commonly experienced during the takeoff and landing phases of MAVs can also degrade performance.

Multiplexing of the array and synthesising a response by the control system can potentially introduce computational complexities, especially with dense arrangements. Finally, these sensors are knowledge-based where they require an in-depth understanding of the airfoil properties in the given flight domain, and require calibration to those conditions, unlike inertial sensors for example that can be easily adopted by any design, in a "plug and play" fashion. 


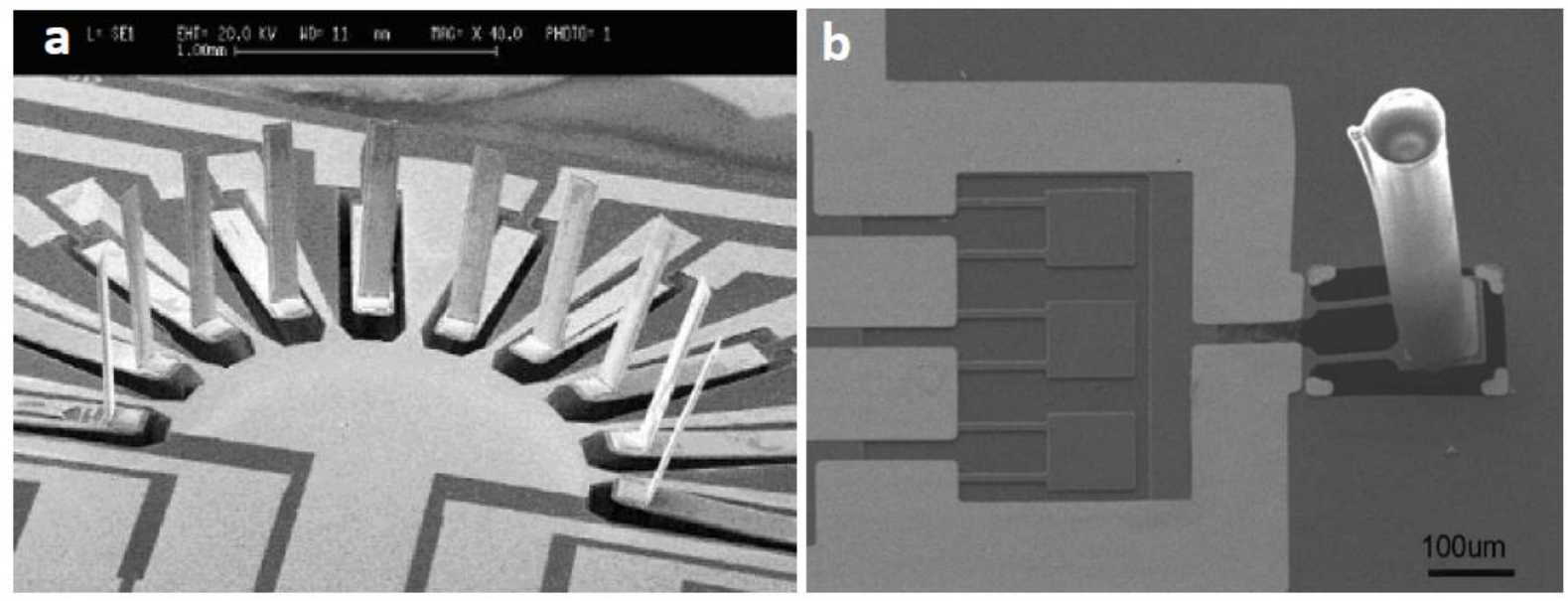

FIGURE 6: MECHANICAL FLOW SENSOR ARRANGEMENTS WITH DIFFERENT OUTPUTS: (A) VELOCITY VECTOR (FAN ET AL., 2002) (B) VELOCITY MAGNITUDE (CHEN ET AL., 2007).
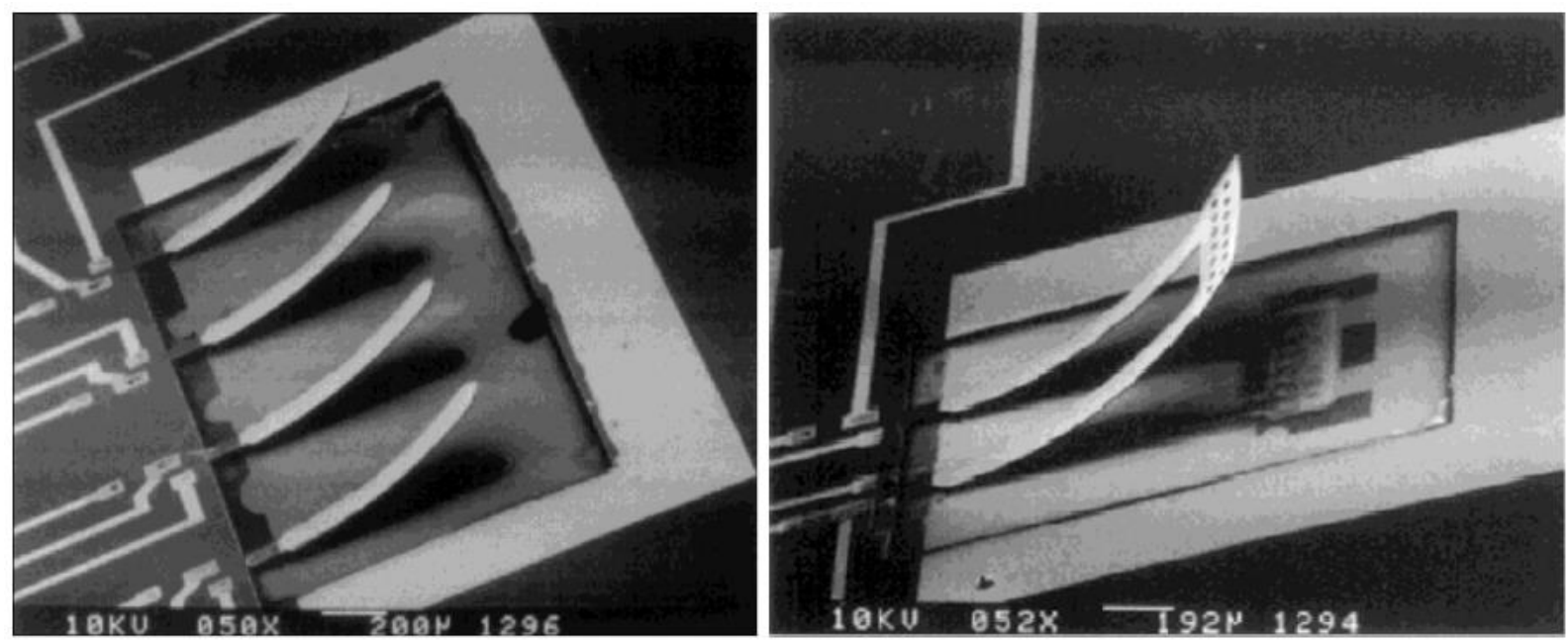

FIGURE 7: CANTILEVERED MEMS FLOW SENSOR (KIM ET AL., 2000).

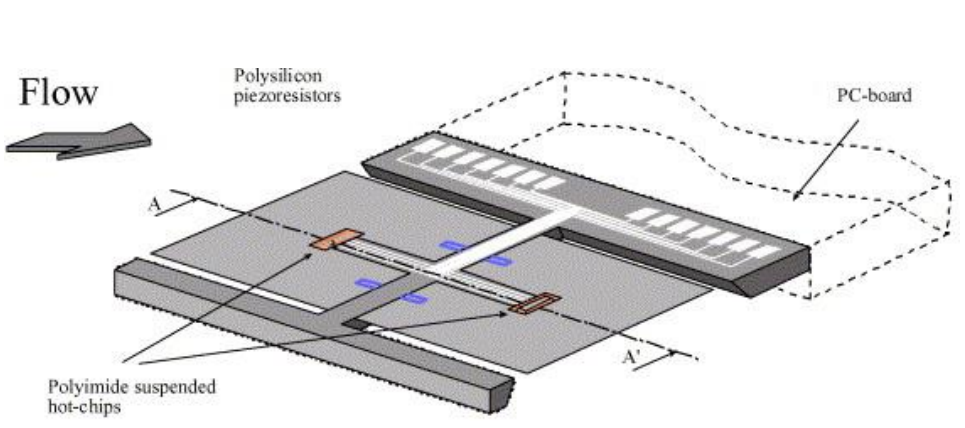

(a)

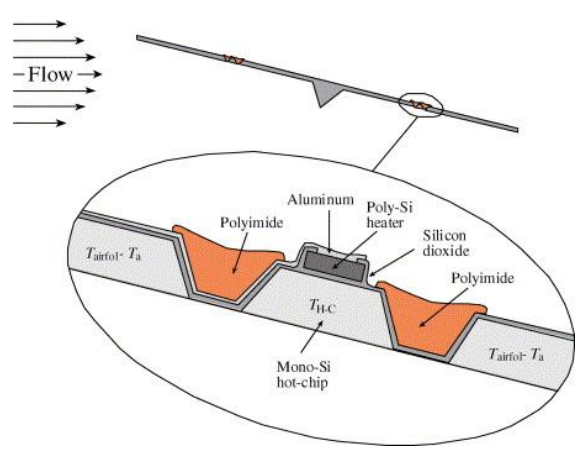

(b)

FIGURE 8: (A) LIFT FORCE FLOW SENSOR (B) SCHEMATIC OF THE FLAT PLATE SENSING ELEMENT (SVEDIN ET AL., 2003B) 


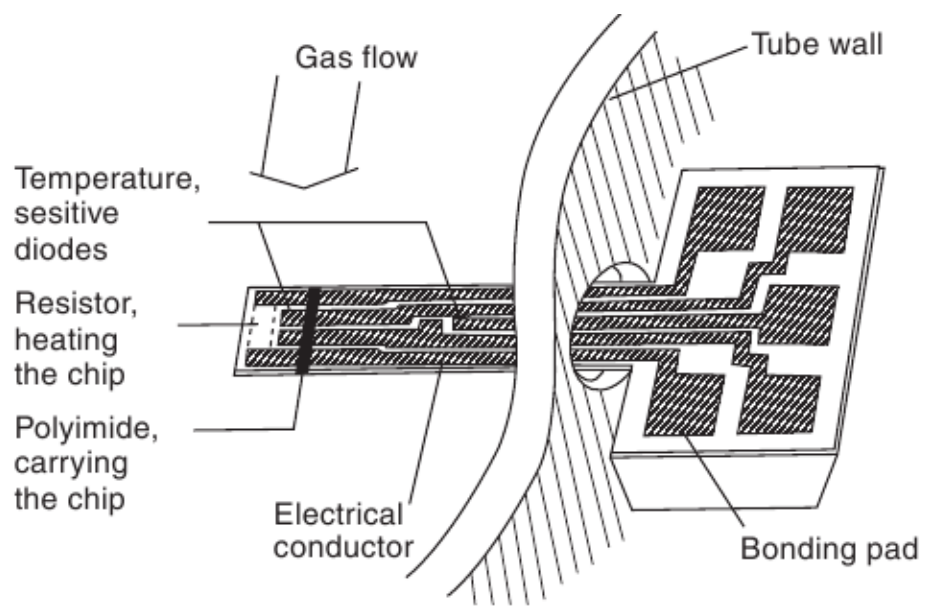

FIGURE 9: MEMS THERMAL BASED FLOW SENSOR SHOWING SEPARATE HEATER AND TEMPERATURE SENSORS (STEMME, 1986) REPRODUCED BY (MCNAMARA AND GIANCHANDANI, 2011).

\subsection{Artificial Hairs}

Strain-based flow sensors can be modified to mimic the function of biological hair. Mimicking insect hairs for adaption to robotics and other applications is receiving a considerable interest by researchers (Dijkstra et al., 2005, Krijnen et al., 2007, Bruinink et al., 2009, Casas et al., 2010, Dagamseh, 2011). The cricket's sensory system sparked the inspiration to develop an artificial capacitive hair-like flow sensor array for flow pattern measurements (see Figure 10). The fundamental concept of these artificial hairs is to resolve mechanical responses induced by viscous drag-torque as a function of space and time. Fabricated using MEMS technology, these artificial hair sensors can be made in different lengths $(100-900 \mu \mathrm{m})$ and widths $(25-80 \mu \mathrm{m})$ with reduced spacing between the hairs thus allowing dense clustering (see Figure 11). It is reported that these physical parameters of the hairs influence their response sensitivity and bandwidth (Dagamseh, 2011). A delicate design balance is hence required to achieve high sensitivity while maintaining sensor bandwidth.

The artificial hairs measure the viscous drag induced by relative motion through a fluid. The hairs are constructed from rows and columns of conductive electrodes, which are separated by dielectrics. The induced torque tilts the base membrane, consequently varying capacitance. The variance in capacitance proportional to the velocity of the artificial hair through the fluid. The sensors were shown to attain high sensitivity to airflow down to a few $\mathrm{mm} / \mathrm{s}$ (Dagamseh, 2011). The stiffness of the sensory hairs can differ for each axis of deflection to provide information on the direction of the velocity vector. 


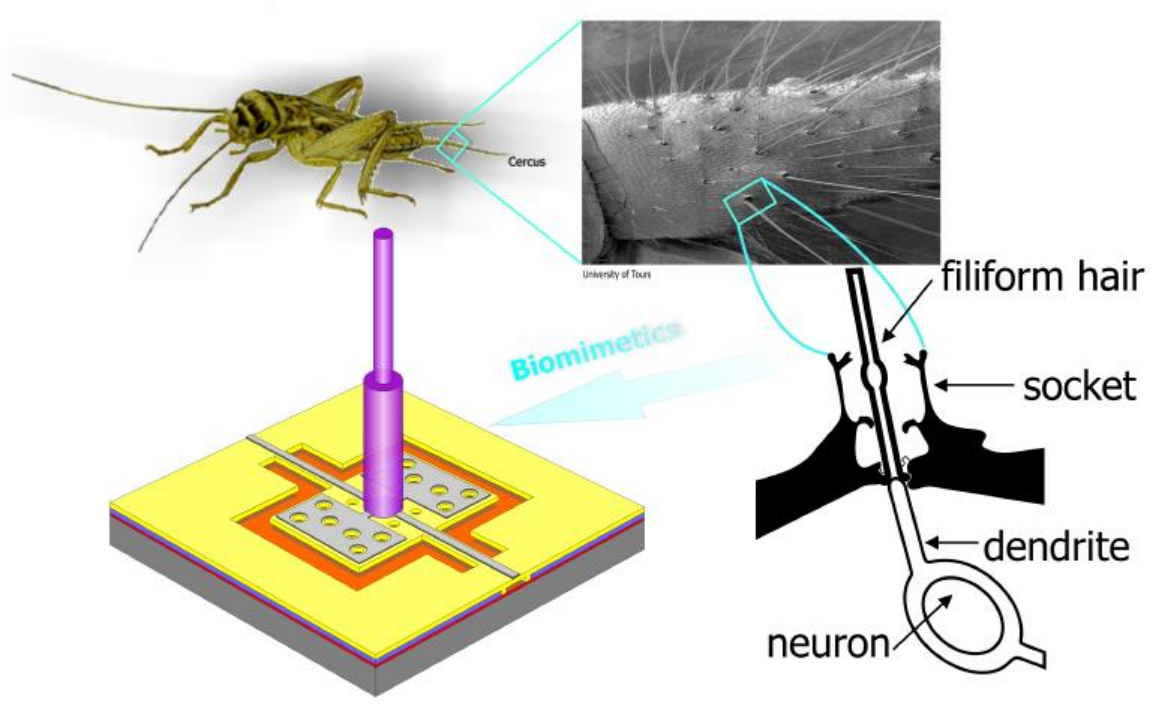

FIGURE 10: HAIR-LIKE SENSOR GEOMETRY AND ITS BIOLOGICAL SOURCE OF INSPIRATION (DAGAMSEH, 2011)

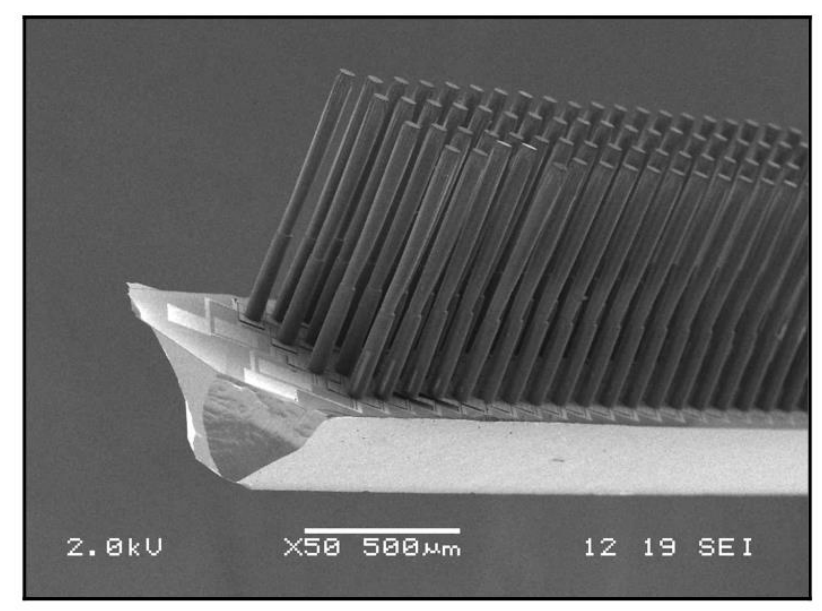

FIGURE 11: SCANNING ELECTRON MICROSCOPE (SEM) IMAGE OF HAIR-LIKE SENSOR ARRAY (KRIJNEN ET AL., 2007)

Dagamseh (2011) states that there are considerable challenges in the design and use of an array of artificial hair sensors. Various issues with electronic interfacing can limit overall performance of the sensory array particularly with real-time measurements. To achieve spatio-temporal flow measurements, hairs are interrogated solitarily, where each hair in an array uses a separate acquisition channel to communicate with a central processor. The larger the array, the better the estimation of the flow properties. The size of the array is constrained by the available processing resources (e.g., clock speed and memory), the hardware (e.g., number and speed of the analogue to digital processors), and wing spaceavailable. Field Programmable Gate Array (FPGA) and other micro-processors capable of parallel processing could address some of these computational and timing issues associated with large sensor arrays.

Issues concerning the size, weight, complexity, and cost must still be addressed before large artificial hair arrays become a feasible sensing technology for MAVs. Finally (Dagamseh, 2011) states that further improvements are required to match the biological cricket hair. 


\subsection{Artificial Covert Feathers}

Another biologically inspired variant of flow sensors comes in the form of covert feather-like wing panels. Blower and Wickenheiser (2010) replicate avian covert feathers and explore their use for gust alleviation. The feather-like panels were installed on the upper and lower wing surface as illustrated in Figure 12. The panels act as sensors, actuators, and load bearing members. The underlying concept is to integrate sensors with aerodynamic surfaces to detect gusts, and alleviate them.

The work by Blower and Wickenheiser (2010) focuses on the use of the panels for flow control rather than their use for flow sensing. For flow sensing, the feather-like panels need to be free to rotate in and out of the boundary layer to allow gusts to pass through the skeletal structure with minimal impedance. Using piezoelectric panel actuation, the panels will achieve enhanced manoeuvrability for gust mitigation. Blower and Wickenheiser (2010) suggest that the concept of aero-braking will permit stable flight in elevated turbulence. Additionally, trajectory deviation is also expected to reduce considerably, allowing air-to-air refuelling of UAS, which requires high manoeuvrability. The research is still in its early stages. Blower and Wickenheiser (2011) have explored the aerodynamic characteristics of the panels using numerical methods. Later papers (Blower et al., 2011), Blower et al. (2012) present results on the development of a dynamic model of the system.

This approach seems to be better suited to larger unmanned aircraft due to the size constraints of MAVs. Furthermore, this sensing approach takes up valuable usable volume in the wings which can be critical for storing energy (i.e. batteries or fuel). There are additional potential disadvantages associated with the complexity of the approach; its aerodynamics (Drag), operation, control and robustness. Failure of one or more panels disrupting the lift distribution could be hazardous. Finally, multiplexing, powering and commanding a panel array would be limited by the available processing and power resources onboard a MAV.

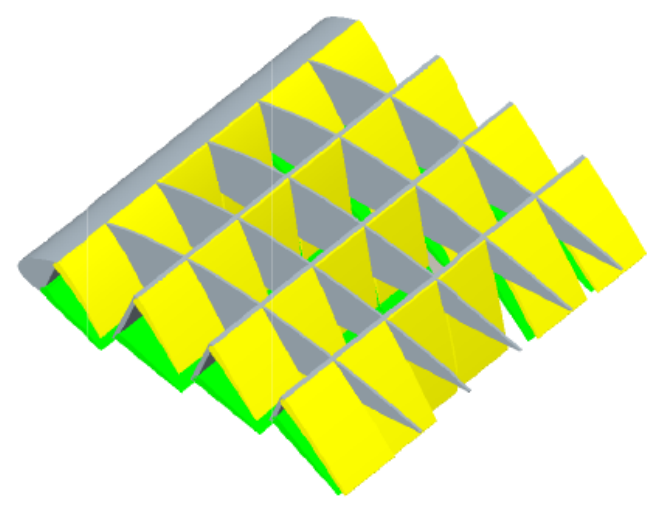

FIGURE 12: GUST ALLEVIATION SYSTEM MIMICKING AVIAN COVERT FEATHERS (BLOWER AND WICKENHEISER, 2011)

\subsection{Pressure sensors}

In nature, feathers act as a deformable membrane, which detect flow disturbances over a wing. Feathers vibrate or deflect during flight due to oncoming gusts. A robust replication of the function of a feather is to implement surface-mounted pressure taps over the wing to sense 
the flow disturbances. The deformation of the sensor's membrane with variation in local pressure, is similar to the feather which deforms with flow instabilities. A pressure sensor could therefore be considered analogous to a feather and its receptor, see Figure 13. The membrane's vibration/deflection is typically measured with capacitance or strain sensors, which are conceptually similar to Herbst corpuscles. Pressure sensors represent another form of strain-based flow sensors. These transducers, are based on diaphragm designs, whereby the use of various physical mechanisms measure the differential across a thin membrane. A description of the most common physical mechanisms employed by the transducers are outlined in Table 3.

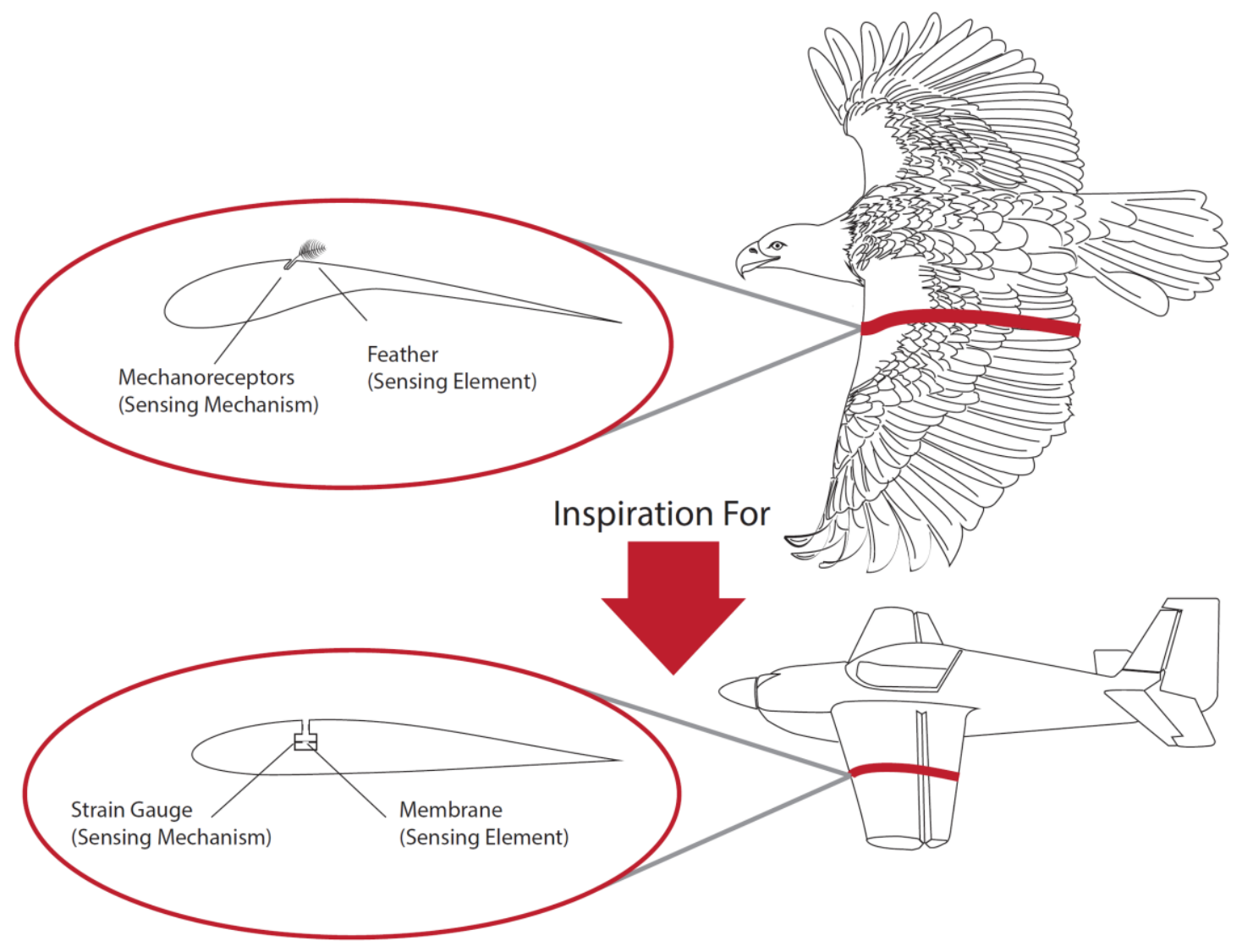

FIGURE 13: BIO-INSPIRED PRESSURE SENSING FOR MAV ATTITUDE CONTROL

TABLE 3: SUMMARY OF PRESSURE SENSOR TYPES

\begin{tabular}{ll}
\hline $\begin{array}{l}\text { Sensor } \\
\text { Type }\end{array}$ & Description \\
\hline Piezoresistive & $\begin{array}{l}\text { Widely used due to simple fabrication. It takes advantage of the piezoelectric effect to measure the } \\
\text { deformation of its peizo-membrane caused by pressure. This allows for dynamic detection of pressure } \\
\text { fluctuations. Its resistors are usually configured in a Wheatstone bridge configuration for improved } \\
\text { voltage output (McNamara and Gianchandani, 2011). These sensors generally suffer from reduced } \\
\text { sensitivity and high temperature drift. Krause (2011) states that this sensor type is rarely feasible for } \\
\text { measuring turbulent flow, although attempts have been made (Kälvesten, 1996). }\end{array}$ \\
Capacitive & $\begin{array}{l}\text { The most common pressure sensory type, which employs a membrane coupled with a sealed cavity } \\
\text { which deforms under applied pressure. The applied pressure is measured by detecting the strain which is } \\
\text { outputted as a capacitance between the membrane and an electrode underlying it. This type of sensor is } \\
\text { greatly researched since it has improved temperature sensitivity, and dynamic range compared to its }\end{array}$ \\
\hline
\end{tabular}


piezoresistive counterpart (Cho et al., 1990, Farooqui and Evans, 1987, Kung and Lee, 1992, Hin-Leung and Wise, 1988). The performance depends on various features of design. There are several design variants of the capacitive pressure sensor permitting improved sensitivity and dynamic range (Park and Gianchandani, 2003, Park and Gianchandani, 2000, Ming-Shuang et al., 2007, Akar et al., 2001, Yamamoto et al., 2002, Daigle et al., 2007). However, capacitive sensors inherently suffer from nonlinearity along with high impedance (McNamara and Gianchandani, 2011, Krause, 2011) in addition to the external power required for operation. Packaging effects, and humidity are considered prime causes of performance reduction or even failures over lifetime (de Groot et al., 2011).

Optical Typically, utilizes an optical fiber which uses a Fabry-Perot interferometer to detect deformations of a silicon membrane attached to its end. This typical approach has several advantages including reduced temperature sensitivity, high linearity, immunity to electromagnetic interference and capability of multiplexing. This sensor type is more suited for array implementations. The setback is the high cost and the use of complicated technologies, although an attempt of using simpler technology is published (Lia et al., 2010). There are also various other variants studied (Abeysinghe et al., 2001, Chih-Wei et al., 2012, Reck et al., 2011).

Tunnelling Implementations are either Based on resonant tunnelling diodes, RTD's, which are sensitive to pressure (Mutamba et al., 1999, Fobelets et al., 1994), or the use of sharp tips near deformable membranes(Chingwen and Najafi, 1994). The latter requires a closed-loop system controlling the tip placement where the force required is the output.

Resonant

Operates by measuring the stress or the damping coefficient induced by a change in resonant frequency which is caused by pressure (Greenwood, 1984, Petersen et al., 1991, Andrews et al., 1993, Welham et al., 1999, Burns et al., 1995, Melvas et al., 2001). For improved performance the vibrating element is sealed in a vacuum to prevent gas damping. Although potentially this sensor has superior precision, it suffers from fabrication complexities, and consequently increased costs. Stiction can also be problematic.

\subsubsection{Surface Embedded Pressure Sensors}

Pressure sensors are largely employed by MAVs as velocity and/or barometric sensors along with an Inertial Measurement Unit (IMU) for navigation. Recently Watkins and Melbourne (2003), drawing inspiration from the function of avian feathers, proposed the use of readily available pressure sensors as an input for MAV attitude control. The concept has been further explored by a number of researchers. Patel et al. (2007), Bowles et al. (2009) explored the time response of pressure sensors for predicting leading edge flow separation, in order to trigger a plasma flow actuator. Cox et al. (2010) also used pressure-based sensing to approximate sectional lift to provide a feedback signal for automated flap control. Barnwell (2003), Lion (2007) studied the effectiveness of a morphing wing type control strategy based on pressure feedback. Pressure-based feedback has also been utilized for guiding a small fixed wing UAV through a hover transition manoeuvre (Yeo et al., 2012). Other attempts involve detecting leading edge flow separation, or predicting angle of attack using specially fabricated pressure or shear sensors, which were imbedded in the wing of an UAV (Xu et al., 2003, Callegari et al., 2006, Fei et al., 2007). More relevantly the feasibility of using the pressure signal from a few well-positioned pressure taps as a control input for MAVs was demonstrated numerically using simulations (Shen and $\mathrm{Xu}, 2013$ ) and statistically using correlation studies (Marino et al., 2012). Finally, Guerreiro and Hubbard Jr (2008) explored the use of pressure information from a few selected positions on a model aircraft for lift distribution control.

This promising concept is innovative and practical whereby it takes advantage of the miniature commercially available pressure transducers; a mature sensing technology for 
measuring flow parameters. This reduces the costs and complexities significantly building on the available technology. However, pressure sensing suffers from operational setbacks challenging its application in MAVs. In the context of attitude control, multiplexing maybe necessary, even with attempts to reduce the number of measurement locations (Marino et al., 2012). Tubing is necessary for sensors not embedded in the wing. Pressure tubing has its own robustness issues in terms of obstruction, and internal volume sensitivity. The dynamic response of tubing is sometimes an issue and whilst dynamic calibration and correction (see Bergh and Tijdeman (1965)) is becoming increasingly commonplace, calibration of different lengths of tubing can introduce further complexities as well as repeatability issues. Maintaining a reference pressure is also problematic due to environmental drift, induced by temperature variation for example. Although, surface embedment of MEMS pressure sensors can eliminate some of the setbacks associated with tubing, it comes at the price of fabrication complexities. Embedding sensors into the wing is limited by the thickness of the MAVs airfoil.

\subsection{Load Sensors}

Load sensors can be used to measure the destabilising effects of flow disturbances on the flight vehicle. These sensors can be replicated using commercially available strain sensors such as strain gauges or piezo film. Such sensors can be utilised in wing load estimation of MAVs to potentially predict the vehicle's attitude. Limited research has been conducted in replicating biological load receptors. Although the time advantage of load sensing is limited, it can still complement a control system, potentially improving attitude estimation.

\section{Discussion}

Investigating novel approaches for attitude sensing in MAVs can potentially create a new generation of less turbulence-prone MAVs. The published literature focuses on improvements of conventional inertial and optical based sensors for extracting further performance gains, rather than investigating novel sensory approaches (Saukoski et al., 2007, Sung et al., 2008, Dong et al., 2006, Miao et al., 2007, Chae et al., 2005, Xiao et al., 2008, Ruffier and Franceschini, 2005, Aubépart and Franceschini, 2007, Kendoul et al., 2009, Chahl et al., 2011, Taylor et al., 2003). The apparent objective of these studies is the extraction of further performance through advancements in signal processing, measurement techniques, and fabrication. It seems from some of the literature that conventional sensors are enough for attitude control. Although this notion is somewhat true for larger Unmanned Aircraft (UA) and commercial aircraft, it is not the only possible turbulence mitigation technique applicable for MAVs, which operate in a more challenging turbulence environment. The majority of the reviewed studies target a diversity of applications with only a few specifically targeting aerial robotics. Thus, opportunities to exploit aerodynamics to explore novel sensory approaches have been missed.

Sensor fusion is evident in animals, where birds and insects employ different transducers feeding the same sensory system, which in return, signals the control system (Taylor and Krapp, 2007). Hence, future MAV automatic guidance and control systems are likely to 
employ multiple sensors, which could be fused together or integrated individually. The review identified the potential benefits of biologically inspired sensors. The potential advantages of using combinations of the reviewed sensors have yet to be explored. Hence, more research focus is required in this area, to extracting further potential performance gains through various sensor combinations.

\section{Conclusion}

Nature has inspired a wide range of emerging sensing techniques applicable to MAVs. It was found that birds and insects use different types of mechanoreceptors tuned for either local flow sensing or total wing-load sensing to assist their flight in high turbulence conditions. Current efforts to replicate the function of these receptors have focussed on flow and pressure-based sensing approaches. Research into flow and pressure-based sensing approaches are still embryonic, with few flight-proven systems. Another biologically inspired sensing opportunity lies in load sensors; however, research into their replication and application to MAVs could not be identified in the literature.

A number of vital research questions and challenges remain for these emerging sensing technologies. The greatest challenge lies in the development of feasible systems that meet the stringent SWaP constraints of MAVs. In particular it is not the sensors themselves, but the auxillary sub-components (hardware, installation, and wiring) and the algorithmic integration (CPUs and novel algorithms) of their measurements that build the gap in attitude stabilisation and control technologies for MAVs. Whilst phase-advanced sensing has the potential to reduce the disturbing effect of turbulence, a more pragmatic research question is in determining the net benefit over traditional inertial/reactive sensing approaches. Answering this question must take into consideration the practical penalties (e.g., SWaP and drag) incurred in implementing biologically inspired systems.

Research has primarily focussed on the replication of single sensors. Nature's flyers do not rely on single sensors. Hence, significant research opportunity lies in the exploration of optimal configuration of single-type sensors (e.g., sensing arrays), combinations of different biologically inspired sensors, and algorithms for multi-sensor fusion.

In summary, there are many new sensing opportunities emerging with potential application to MAVs. The primary challenge is in their practical construction and implementation at small scales. However, if the current trend in technology-miniaturisation continues, then this challenge is likely to be quickly overcome.

\section{References}

ABEYSINGHE, D. C., DASGUPTA, S., BOYD, J. T. \& JACKSON, H. E. 2001. A novel MEMS pressure sensor fabricated on an optical fiber. IEEE Photonics Technology Letters, 13, 993-995. 
AI, H., YOSHIDA, A. \& YOKOHARI, F. 2010. Vibration receptive sensilla on the wing margins of the silkworm moth Bombyx mori. Journal of Insect Physiology, 56, 236246.

AKAR, O., AKIN, T. \& NAJAFI, K. 2001. A wireless batch sealed absolute capacitive pressure sensor. Sensors and Actuators A: Physical, A95, 29-38.

ANDO, N., WANG, H., SHIRAI, K., KIGUCHI, K. \& KANZAKI, R. 2011. Central projections of the wing afferents in the hawkmoth, Agrius convolvuli. Journal of Insect Physiology, 57, 1518-1536.

ANDRES, K. \& VON DURING, M. 1990. Comparative and functional aspects of the histological organization of cutaneous receptors in vertebrates. The Primary Afferent Neuron: A Survey of Recent Morpho-functional Aspects. Plenum Press, New York, 117.

ANDREWS, M. K., TURNER, G. C., HARRIS, P. D. \& HARRIS, I. M. 1993. A resonant pressure sensor based on a squeezed film of gas. Sensors and Actuators A: Physical, A36, 219-226.

AUBÉPART, F. \& FRANCESCHINI, N. 2007. Bio-inspired optic flow sensors based on FPGA: Application to Micro-Air-Vehicles. Microprocessors and Microsystems, 31, 408-419.

BARNWELL, W. 2003. UAV Flight Control Using Distributed Actuation and Sensing. Masters Thesis, North Carolina State University

BERGH, H. \& TIJDEMAN, H. 1965. Theoretical and experimental results for the dynamic response of pressure measuring systems, Nationaal lucht-en ruimtevaartlaboratorium.

BLOWER, C. J., LEE, W. \& WICKENHEISER, A. M. 2011. The development of a closedloop flight controller with panel method integration for gust alleviation using biomimetic feathers on aircraft wings. ASME Conference on Smart Materials, Adaptive Structures and Intelligent Systems. Pheonix, AZ.

BLOWER, C. J., LEE, W. \& WICKENHEISERA, A. M. The development of a closed-loop flight controller with panel method integration for gust alleviation using biomimetic feathers on aircraft wings. Proceedings of SPIE, March 11-15 2012 San Diego, CA.

BLOWER, C. J. \& WICKENHEISER, A. M. 2010. Biomimetic Feather Structures for Localized Flow Control and Gust Alleviation on Aircraft Wings. 21st International Conference on Adaptive Structures and Technologies. State College, PA.

BLOWER, C. J. \& WICKENHEISER, A. M. Two-dimensional localized flow control using distributed, biomimetic feather structures: a comparative study. Proceedings of SPIE, March 6-10 2011 San Diego, CA. 1-10.

BOWLES, P. O., CORKE, T. C. \& MATLIS, E. Stall detection on a leading-edge plasma actuated pitching airfoil utilizing onboard measurement. Proc. 47th Aerospace Sciences Meeting, 2009. 5-8.

BROWN, R. E. \& FEDDE, M. R. 1993. Airflow sensors in the avian wing. Journal of Experimental Biology, 179, 13-13.

BRUININK, C., JAGANATHARAJA, R., DE BOER, M., BERENSCHOT, E., KOLSTER, M., LAMMERINK, T., WIEGERINK, R. \& KRIJNEN, G. Advancements in technology and design of biomimetic flow-sensor arrays. In: Proceedings of the 22nd IEEE International Conference on MEMS, 25-29 Jan 2009 Sorrento, Italy. 152-155.

BUDER, U., BERNS, A., OBERMEIER, E., PETZ, R. \& NITSCHE, W. 2005. AeroMEMS wall hot-wire anemometer on polyimide foil for measurement of high frequency fluctuations. Sensors, 2005 IEEE.

BUDER, U., BERNS, A., PETZ, R., NITSCHE, W. \& OBERMEIER, E. 2007. AeroMEMS Wall Hot-Wire Anemometer on Polyimide Substrate Featuring Top Side or Bottom Side Bondpads. Sensors Journal, IEEE, 7, 1095-1101. 
BURNS, D. W., ZOOK, J. D., HORNING, R. D., HERB, W. R. \& GUCKEL, H. 1995. Sealed-cavity resonant microbeam pressure sensor. Sensors and Actuators A: Physical, A48, 179-186.

CALLEGARI, S., ZAGNONI, M., GOLFARELli, A., TARTAGNI, M., TALAMELLI, A., PROLI, P. \& ROSSETTI, A. 2006. Experiments on aircraft flight parameter detection by on-skin sensors. Sensors and Actuators A: Physical, 130, 155-165.

CAMHI, J. M. 1969. Locust wind receptors I. Transducer mechanics and sensory response. Journal of Experimental Biology, 50, 335-348.

CASAS, J., STEINMANN, T. \& KRIJNEN, G. 2010. Why do insects have such a high density of flow-sensing hairs? Insights from the hydromechanics of biomimetic MEMS sensors. Journal of the Royal Society interface, 7, 1487-1495.

CHAE, J., KULAH, H. \& NAJAFI, K. 2005. A CMOS-compatible high aspect ratio siliconon-glass in-plane micro-accelerometer. Journal of Micromechanics and Microengineering, 15, 336.

CHAHL, J., ROSSER, K. \& MIZUTANI, A. Bioinspired optical sensors for unmanned aerial systems. Proceedings of SPIE, 2011. 797503.

CHEN, J., ZOU, J. \& LIU, C. A surface micromachined, out-of-plane anemometer. In: Proceedings of the 15th IEEE International Conference on MEMS, January $2002 \mathrm{NV}$, USA. IEEE, 332-335.

CHEN, N., TUCKER, C., ENGEL, J. M., YINGCHEN, Y., PANDYA, S. \& CHANG, L. 2007. Design and Characterization of Artificial Haircell Sensor for Flow Sensing With Ultrahigh Velocity and Angular Sensitivity. Journal of Microelectromechanical Systems, 16, 999-1014.

CHIH-WEI, L., YU-LUNG, L., JIAHN-PIRING, Y. \& CHIN-HO, C. 2012. Application of Fiber Bragg Grating Level Sensor and Fabry-Pérot Pressure Sensor to Simultaneous Measurement of Liquid Level and Specific Gravity. IEEE Sensors Journal, 12, 827831.

CHINGWEN, Y. \& NAJAFI, K. Bulk-silicon tunneling-based pressure sensors. Proceedings of the 1994 Solid-state Sensor and Actuator Workshop, 13-16 June 1994 Hilton Head Island, SC, USA. Transducer Research Foundation, 201-208.

CHO, S. T., NAJAFI, K. \& WISE, K. D. 1990. Secondary sensitivities and stability of ultrasensitive silicon pressure sensors. Tech Digest, Solid-State Sensor and Actuator Workshop. Hilton Head Island, SC, USA.

COX, C., GOPALARATHNAM, A. \& HALL, C. E. 2010. Flight Test of Stable Automated Cruise Flap for an Adaptive Wing Aircraft. Journal of Aircraft, 47, 1178-1188.

CROON, G. C. H. E. D., GROEN, M. A., WAGTER, C. D., REMES, B., RUIJSINK, R. \& OUDHEUSDEN, B. W. V. 2012. Design, aerodynamics and autonomy of the DelFly. Bioinspiration \& Biomimetics, 7, 025003.

DAGAMSEH, A. 2011. Bio-Inspired hair flow sensor arrays from nature to MEMS. $\mathrm{PhD}$ thesis, University of Twente.

DAIGLE, M., CORCOS, J. \& KE, W. 2007. An analytical solution to circular touch mode capacitor. IEEE Sensors Journal 7, 502-505.

DE GROOT, W., FELNHOFER, D. \& GUSEV, E. 2011. Reliability Aspects of Capacitive MEMS Devices. Procedia Engineering, 25, 180-186.

DIJKSTRA, M., VAN BAAR, J., WIEGERINK, R., LAMMERINK, T., DE BOER, J. \& KRIJNEN, G. 2005. Artificial sensory hairs based on the flow sensitive receptor hairs of crickets. Journal of Micromechanics and Microengineering, 15, S132.

DONG, H., HAO, Y., SHEN, S., HE, L. \& LEI, J. A novel out-of-plane MEMS tunneling accelerometer with excellent low frequency resolution. 2006. IEEE, 821-825. 
EBEFORS, T., KALVESTEN, E. \& STEMME, G. Three dimensional silicon triple-hot-wire anemometer based on polyimide joints. In: Proceedings of the 11th IEEE International Workshop on MEMS, 25-29 January 1998 Heidelberg, Germany. 93-98.

ELSON, R. C. 1987. Integration of wing proprioceptive and descending exteroceptive sensory inputs by thoracic interneurones of the locust. Journal of Experimental Biology, 128, 193-217.

FAN, Z., CHEN, J., ZOU, J., BULLEN, D., LIU, C. \& DELCOMYN, F. 2002. Design and fabrication of artificial lateral line flow sensors. Journal of Micromechanics and Microengineering, 12, 655-661.

FAROOQUI, M. M. \& EVANS, A. G. R. 1987. A polysilicon-diaphragm-based pressure sensor technology. Journal of Physics E: Scientific Instruments, 20, 1469-1471.

FEI, H., ZHU, R., ZHOU, Z. \& WANG, J. 2007. Aircraft flight parameter detection based on a neural network using multiple hot-film flow speed sensors. Smart materials and structures, 16, 1239.

FOBELETS, K., VOUNCKX, R. \& BORGHS, G. 1994. A GaAs pressure sensor based on resonant tunnelling diodes. Journal of Micromechanics and Microengineering, 4, 123128.

GALIŃSKI, C. \& ŻBIKOWSKI, R. 2007. Some problems of micro air vehicles development. Bulletin of the polish academy of sciences; technical sciences, 55, 91-98.

GALINSKI, C. R. 2006. Gust Resistant Fixed Wing Micro Air Vehicle. Journal of Aircraft, 43, 1586-1588.

GASS, V., VAN DER SCHOOT, B. \& DE ROOIJ, N. Nanofluid handling by micro-flowsensor based on drag force measurements. In: Proceedings of the IEEE MEMS Workshop 93, Feb 1993 FL, USA. 167-172.

GOTTSCHALDT, K. M. 1985. Structure and function of avian somatosensory receptors. In Form and Function in Birds, London, UK, Academic Press.

GREENWOOD, J. C. 1984. Etched silicon vibrating sensor. Journal of Physics E: Scientific Instruments, 17, 650-652.

GUERREIRO, N. M. \& HUBBARD JR, J. E. 2008. Pressure Port Placement for Lift Distribution Measurement on a Model Aircraft with Optimized Trailing-Edge Flaps. 26th AIAA Applied Aerodynamics Conference. Honolulu, Hawaii.

HANKIN, E. H. 1913. Animal Flight: A Record of Observation, London, UK, ILIFFE.

HIN-LEUNG, C. \& WISE, K. D. 1988. An ultraminiature solid-state pressure sensor for a cardiovascular catheter. IEEE Transactions on Electron Devices, 35, 2355-2362.

HÖRSTER, W. 1990a. Histological and electrophysiological investigations on the vibrationsensitive receptors (Herbst corpuscles) in the wing of the pigeon (Columba livia). Journal of Comparative Physiology A: Neuroethology, Sensory, Neural, and Behavioral Physiology, 166, 663-673.

HÖRSTER, W. 1990b. Vibrational sensitivity of the wing of the pigeon (Columba livia ) - a study using heart rate conditioning. Journal of Comparative Physiology A: Neuroethology, Sensory, Neural, and Behavioral Physiology, 167, 545-549.

IGGO, A. \& GOTTSCHALDT, K. M. Cutaneous mechanoreceptors in simple and in complex sensory structures. Rheinisch-Wesfälishe Akademie der Wis-senschaften Abhandlung, 1974. 153-176.

KÄLVESTEN, E. 1996. Pressure and Wall Shear Stress Sensors for Turbulence Measurements. PhD thesis, Royal Institute of Technology.

KENDOUL, F., FANTONI, I. \& NONAMI, K. 2009. Optic flow-based vision system for autonomous 3D localization and control of small aerial vehicles. Robotics and Autonomous Systems, 57, 591-602. 
KIM, D.-K., KANG, S.-G., PARK, J.-Y., SIM, J.-H., SHIN, J.-K., CHOI, P. \& LEE, J.-H. 2000. Characteristics of piezoresistive mass flow sensor fabricated by porous silicon micromachining. Japanese Journal of Applied Physics, 39, 7134-7137.

KIM, S., KIM, Y. \& PARK, S. 2003. A circular-type thermal flow direction sensor free from temperature compensation. Sensors and Actuators A: Physical, A108, 64-68.

KIM, S., NAM, T. \& PARK, S. 2004. Measurement of flow direction and velocity using a micromachined flow sensor. Sensors and Actuators A: Physical, 114, 312-318.

KRAUSE, J. S. 2011. Micromachined microphone array on a chip for turbulent boundary layer measurements. $\mathrm{PhD}$ thesis, Tufts University.

KRIJNEN, G., LAMMERINK, T., WIEGERINK, R. \& CASAS, J. Cricket inspired flowsensor arrays. In: Proceedings of the 6th IEEE Conference on Sensors, 28-31 Oct 2007 ATL, USA. 539-546.

KUNG, J. T. \& LEE, H. S. 1992. An integrated air-gap-capacitor pressure sensor and digital readout with sub-100 attofarad resolution. Journal of Microelectromechanical Systems, 1, 121-129.

LEVIN, J. E. \& MILLER, J. P. 1996. Broadband neural encoding in the cricket cereal sensory system enhanced by stochastic resonance. Nature, 380, 165-168.

LIA, X.-J., QIU, C.-J., DENG, Y.-L., QU, W. \& HE, J.-N. 2010. An MEMS Optical Fiber Pressure Sensor Based on a Square Silicon Diaphragm: Numerical Simulation and Experimental Verification. International Journal of Nonlinear Sciences and Numerical Simulation, 11, 225-229.

LION, S. 2007. Control Authorities of a distributed Actuation and Sensing Array on a Blended-Wing-Body Uninhabited Aerial Vehicle. Masters Thesis, North Carolina State University.

LISSAMAN, P. 2009. Effects of Turbulence on Bank Upsets of Small Flight Vehicles. 47th AIAA Aerospace Sciences Meeting including The New Horizons Forum and Aerospace Exposition. American Institute of Aeronautics and Astronautics.

LOFDAHL, L., STEMME, G. \& JOHANSSON, B. 1989. Sensor based on silicon technology for turbulence measurements. Journal of Physics E. Scientific Instruments, 22, 391393.

MAIER, A. 1992. Sensory and motor innervation of bird intrafusal muscle fibers. Comparative Biochemistry and Physiology Part A: Physiology, 103, 635-639.

MAIER, A., DE SANTIS, M. \& ELDRED, E. 1971. Absence of muscle spindles in avian extraocular muscles. Experimental Eye Research, 12, 251-253.

MARINO, M., RAVI, S. \& WATKINS, S. 2012. Optimum location of pressure measurments around a wing as a dynamic control input in smooth and turbulent conditions. 28th International Congress of the Aeronautical Sciences.

MCCARLEY, J. S. \& WICKENS, C. D. 2004. Human factors concerns in UAV flight. University of Illinois at Urbana-Champaign Institute of Aviation, Aviation Human Factors Division.

MCNAMARA, S. \& GIANCHANDANI, Y. B. 2011. 5.12 - MEMS-Based Sensors. Comprehensive Semiconductor Science and Technology, 5, 527-559.

MELVAS, P., KALVESTEN, E. \& STEMME, G. A surface micromachined resonant beam pressure sensor. In: Proceedings 14th IEEE International Conference on MEMS, 2001 Interlaken, Switzerland.

MIAO, M., HU, Q., HAO, Y., DONG, H., WANG, L., SHI, Y. \& SHEN, S. A Bulk Micromachined Si-on-glass Tunneling Accelerometer with Out-of-plane Sensing Capability. In: Proceedings of the 2nd IEEE International Conference on NEMS, 1619 Jan 2007. IEEE, 235-240. 
MICHELSON, R. C. 2010. Overview of Micro Air Vehicle System Design and Integration Issues. Encyclopedia of Aerospace Engineering. john Wiley \& Sons, Ltd.

MING-SHUANG, J., CHIA-CHU, C. \& LIN, C. C. K. 2007. An implantable capacitive pressure sensor for biomedical applications. Sensors and Actuators A: Physical, 134, 382-388.

MOHAMED, A., CLOTHIER, R., WATKINS, S., SABATINI, R. \& ABDULRAHIM, M. 2014a. Fixed-Wing MAV Attitude Stability in Atmospheric Turbulence PART 1: Suitability of Conventional Sensors Progress in Aerospace Sciences (Accepted).

MOHAMED, A., MASSEY, K., WATKINS, S. \& CLOTHIER, R. 2014b. The Attitude Control of Fixed-Wing MAVS in Turbulent Environments. Progress in Aerospace Sciences, 66, 37-48.

MUTAMBA, K., FLATH, M., SIGURDARDOTTIR, A., VOGT, A. \& HARTNAGEL, H. L. 1999. A GaAs pressure sensor with frequency output based on resonant tunneling diodes. IEEE Transactions on Instrumentation and Measurement 48, 1333-1337.

NACHTIGALL, W. \& KEMPF, B. 1971. Vergleichende Untersuchungen zur Flugbiologischen Funktion des Daumenfittichs (Alula spuria) bei Vögeln. Journal of Comparative Physiology A: Neuroethology, Sensory, Neural, and Behavioral Physiology, 71, 326-341.

NAKATA, T., LIU, H., TANAKA, Y., NISHIHASHI, N., WANG, X. \& SATO, A. 2011. Aerodynamics of a bio-inspired flexible flapping-wing micro air vehicle. Bioinspiration \& Biomimetics, 6, 045002.

NECKER, R. 1985a. Observations on the function of a slowly adapting mechanoreceptor associated with filoplumes in the feathered skin of pigeons. Journal of Comparative Physiology, 156, 391-394.

NECKER, R. 1985b. Receptors in the skin of the wing of the pigeon and their possible role in bird flight. Biona Report 3, Bird Flight - Vogelflug (ed. W. Nachtigall). Stuttgart: Gustav Fischer.

O'HARA, R. P. \& PALAZOTTO, A. N. 2012. The morphological characterization of the forewing of the Manduca sexta species for the application of biomimetic flapping wing micro air vehicles. Bioinspiration \& Biomimetics, 7, 046011.

OHNSTEIN, T. R., JOHNSON, R. G., HIGASHI, R. E., BURNS, D. W., HOLMEN, J. O., SATREN, E. A., JOHNSON, G. M., BICKING, R. E. \& JOHNSON, S. D. Environmentally rugged, wide dynamic range microstructure airflow sensor. 4th Technical Digest, IEEE Solid-State Sensor and Actuator Workshop, 4-7 Jun 1990. 158-160.

ORR, M., RASMUSSEN, S., KARNI, E. \& BLAKE, E. 2005. Framework for developing and evaluating MAV control algorithms in a realistic urban setting. American Control Conference. Portland, OR USA.

OSTMANN, O. W., RINGER, R. K. \& TETZLAFF, M. 1963. The anatomy of the feather follicle and its immediate surroundings. Poultry Science, 42, 958-969.

PARK, J.-S. \& GIANCHANDANI, Y. B. 2003. A servo-controlled capacitive pressure sensor using a capped-cylinder structure microfabricated by a three-mask process. Journal of Microelectromechanical Systems, 12, 209-220.

PARK, J. S. \& GIANCHANDANI, Y. B. 2000. A capacitive absolute-pressure sensor with external pick-off electrodes. Journal of Micromechanics and Microengineering, 10, 528-533.

PARK, S., KIM, S., KIM, S. \& KIM, Y. 2003. A flow direction sensor fabricated using MEMS technology and its simple interface circuit. Sensors and Actuators B: Chemical, 91, 347-352. 
PATEL, M. P., SOWLE, Z. H., CORKE, T. C. \& HE, C. 2007. Autonomous sensing and control of wing stall using a smart plasma slat. Journal of aircraft, 44, 516-527.

PETERSEN, K., POURAHMADI, F., BROWN, J., PARSONS, P., SKINNER, M. \& TUDOR, J. Resonant beam pressure sensor fabricated with silicon fusion bonding. In: Proceedings of the 5th International Conference on Solid-State Sensors and Actuators (TRANSDUCERS '91), 24-27 Jun 1991 CA, USA. 664-667.

RADHAKRISHNAN, S. \& LAL, A. In-channel micromechanical drag flow sensor with electronic readout. In: Proceedings of the 16th Annual International Conference on MEMS, 19-23 Jan 2003. IEEE, 307-310.

RADHAKRISHNAN, S. \& LAL, A. 2005. Scalable microbeam flowsensors with electronic readout. Journal of Microelectromechanical Systems, 14, 1013-1022.

RECK, K., THOMSEN, E. V. \& HANSEN, O. 2011. MEMS Bragg grating force sensor. Optics Express, 19, 19190--19198.

RUFFIER, F. \& FRANCESCHINI, N. 2005. Optic flow regulation: the key to aircraft automatic guidance. Robotics and Autonomous Systems, 50, 177-194.

SAUKOSKI, M., AALTONEN, L. \& HALONEN, K. A. I. 2007. Zero-rate output and quadrature compensation in vibratory MEMS gyroscopes. IEEE Sensors Journal, 7, $1639-1652$.

SHANG, J. K., COMBES, S. A., FINIO, B. M. \& WOOD, R. J. 2009. Artificial insect wings of diverse morphology for flapping-wing micro air vehicles. Bioinspiration \& Biomimetics, 4, 036002.

SHEN, H. \& XU, Y. 2013. Pressure and Shear Information based Three-Axis Attitude Control for a Micro Air Vehicle. AIAA Atmospheric Flight Mechanics (AFM) Conference. American Institute of Aeronautics and Astronautics.

SHYY, W., AONO, H., CHIMAKURTHI, S. K., TRIZILA, P., KANG, C.-K., CESNIK, C. E. \& LIU, H. 2010. Recent progress in flapping wing aerodynamics and aeroelasticity. Progress in Aerospace Sciences, 46, 284-327.

SMOLA, U. 1970. Rezeptor-und Aktionspotentiale der Sinneshaare auf dem Kopf der Wanderheuschrecke Locusta migratoria. Journal of Comparative Physiology A: Neuroethology, Sensory, Neural, and Behavioral Physiology, 70, 335-348.

SRINIVASAN, M. V., CHAHL, J. S., WEBER, K., VENKATESH, S., NAGLE, M. G. \& ZHANG, S. W. 1999. Robot navigation inspired by principles of insect vision. Robotics and Autonomous Systems, 26, 203-216.

STAMMER, A. 1961. Die Nervenendorgane der Vogelhaut, Szegedi Ny.

STEMME, G. N. 1986. A monolithic gas flow sensor with polyimide as thermal insulator. Electron Devices, IEEE Transactions on, 33, 1470-1474.

STURKIE, P. D. \& WHITTOW, G. C. 2000. Sturkie's Avian Physiology, Academic Press.

SUNG, W. T., SUNG, S., LEE, J. Y., KANG, T., LEE, Y. J. \& LEE, J. G. 2008. Development of a lateral velocity-controlled MEMS vibratory gyroscope and its performance test. Journal of Micromechanics and Microengineering, 18, 055028.

SVEDIN, N., KALVESTEN, E., STEMME, E. \& STEMME, G. 1998a. A new silicon gasflow sensor based on lift force. Journal of Microelectromechanical Systems, 7, 303308.

SVEDIN, N., KÄLVESTEN, E., STEMME, E. \& STEMME, G. 1998b. A lift-force flow sensor designed for acceleration insensitivity. Sensors and Actuators A: Physical, 68, 263-268.

SVEDIN, N., KALVESTEN, E. \& STEMME, G. 2003a. A new edge-detected lift force flow sensor. Journal of Microelectromechanical Systems, 12, 344-354. 
SVEDIN, N., KÄLVESTEN, E. \& STEMME, G. 2003b. A lift force sensor with integrated hot-chips for wide range flow measurements. Sensors and Actuators A: Physical, 109, 120-130.

TAN, Z., SHIKIDA, M., HIROTA, M., XING, Y., SATO, K., IWASAKI, T. \& IRIYE, Y. 2007. Characteristics of on-wall in-tube flexible thermal flow sensor under radially asymmetric flow condition. Sensors and Actuators, A: Physical, 138, 87-96.

TAYLOR, B., BIL, C., WATKINS, S. \& EGAN, G. 2003. Horizon Sensing Attitude Stabilisation: A VMC Autopilot. 18th International UAV Systems Conference. Bristol, UK.

TAYLOR, G. K. \& KRAPP, H. G. 2007. Sensory systems and flight stability: what do insects measure and why? Advances in insect physiology, 34, 231-316.

TENNEKES, H. (ed.) 2009. The Simple Science of Flight : from insects to jumbo jets, London, England: The MIT Press.

THOMPSON, M., WATKINS, S., WHITE, C. \& HOLMES, J. 2011. Span-wise wind fluctuations in open terrain as applicable to small flying craft. The Aeronautical Journal, 115, 693-701.

WALSHE, D. E. J. 1972. Wind-Excited Oscillation of Structures. Her Majesty's Stationery Office.

WATKINS, S. \& MELBOURNE, W. 2003. Atmospheric Winds: Implications for MAVs. Unmanned Air Vehicle Systems, 18th International Conference. University of Bristol, Bristol, UK.

WATKINS, S., MILBANK, J. \& LOXTON, B. 2006. Atmospheric winds and their effects on micro air vehicles. AIAA Journal, 44, 2591-2600.

WELHAM, C. J., GREENWOOD, J. C. \& BERTIOLI, M. M. 1999. A high accuracy resonant pressure sensor by fusion bonding and trench etching. Sensors and Actuators A: Physical, A76, 298-304.

WHITE, C., WATKINS, S., LIM, E. W. \& MASSEY, K. 2012. The Soaring Potential of a Micro Air Vehicle in an Urban Environment. International Journal of Micro Aerial Vehicles, 4, 1-13.

WINKELMANN, R. \& MYERS III, T. T. 1961. The histochemistry and morphology of the cutaneous sensory end organs of the chicken. The Journal of comparative neurology, 117, 27-35.

XIAO, F., CHE, L., XIONG, B., WANG, Y., ZHOU, X., LI, Y. \& LIN, Y. 2008. A novel capacitive accelerometer with an eight-beam-mass structure by self-stop anisotropic etching of $\left(\begin{array}{lll}1 & 0 & 0\end{array}\right)$ silicon. Journal of Micromechanics and Microengineering, 18, 075005.

XU, Y., JIANG, F., NEWBERN, S., HUANG, A., HO, C.-M. \& TAI, Y.-C. 2003. Flexible shear-stress sensor skin and its application to unmanned aerial vehicles. Sensors and Actuators A: Physical, 105, 321-329.

YAMAMOTO, S., NAKAO, O. \& NISHIMURA, H. Touch mode capacitive pressure sensor for passive tire monitoring system. Proceedings of the IEEE Sensors Conference, 2002 FL, USA. IEEE.

YEO, D., ATKINS, E. M., BERNAL, L. P. \& SHYY, W. 2012. Aerodynamic Sensing for a Fixed Wing UAS Operating at High Angles of Attack. AIAA Atmospheric Flight Mechanics Conference. Minneapolis, Minnesota.

ZBIKOWSKI, R. 2004. Sensor-rich feedback control: a new paradigm for flight control inspired by insect agility. Instrumentation \& Measurement Magazine, IEEE, 7, 19-26. 